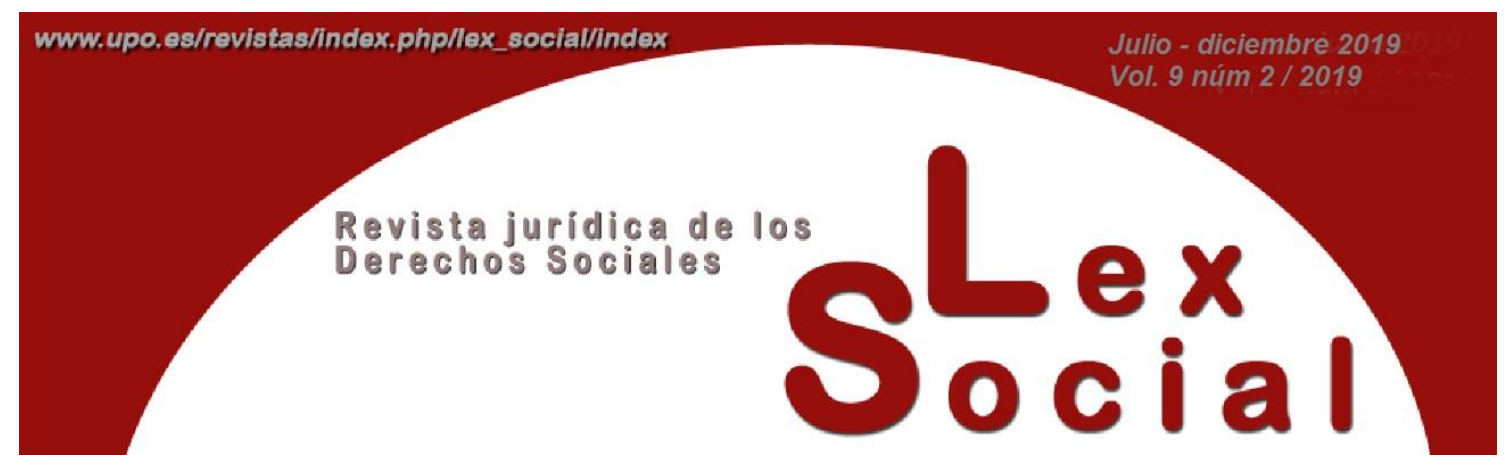

\title{
EL CONTRATO A TIEMPO PARCIAL: REFLEXIONES SOBRE SU RÉGIMEN JURÍDICO, FLEXIBILIDAD Y PRECARIEDAD*
}
PART-TIME CONTRACT: THOUGHTS ON ITS LEGAL STATUS, FLEXIBILITY AND PRECARIOUSNESS

\author{
JUAN ANTONIO ALTÉS TÁRREGA 1 \\ Profesor Titular de Derecho del Trabajo y de la Seguridad Social \\ Universitat de València. Estudi General
}

Artículo recibido el 15 de mayo de 2019

Artículo aceptado el 24 de mayo de 2019

\begin{abstract}
RESUMEN
El presente trabajo toma en consideración que el trabajo a tiempo parcial es un buen instrumento que permite mayor libertad en la configuración del tiempo de trabajo, beneficiando tanto empresas como trabajadores. Sin embargo, en España, la realidad es que las más de las veces es un ejemplo de trabajo precario impuesto a los trabajadores. Por ello, se analiza el régimen jurídico de esta modalidad contractual con el fin de identificar aquellos aspectos que impiden esta funcionalidad, al tiempo que se proponen cambios en la forma de regular que reviertan esta situación.
\end{abstract}

Palabras Clave: contrato a tiempo parcial, voluntariedad, trabajo precario.

\footnotetext{
* Trabajo realizado en el marco del I+D de Generación del Conocimiento sobre Violencia, Trabajo y Género (VITRAGE), Ref. PGC2018-094912-B-I00, del Programa Estatal de Generación de Conocimiento y fortalecimiento científico y tecnológico del sistema de $\mathrm{I}+\mathrm{D}+\mathrm{i}$ del Ministerio de Ciencia, Innovación e Universidades.

${ }^{1}$ ORCID: 0000-0003-1530-8545

ISSN: 2174-6419

Lex Social, vol. 9, núm. 2 (2019)
} 


\begin{abstract}
This paper takes into account that part-time contracts work are a good instrument that allows greater freedom to configure the working time, benefiting both businesses and workers. Nevertheless, the fact is that in most times is an example of precarious work. Therefore, the legal status of this type of contract is analysed in order to identify those elements that stand in the way of this functionality. At the same time, some changes are proposed to reverse this situation.
\end{abstract}

KEYWORDS: part-time contract, voluntary, precarious work.

\title{
SUMARIO
}

1. Introducción.

2. El contrato a tiempo parcial: un recurso para la contratación estable y de calidad.

2.1 Ventajas empresariales: la flexibilidad empresarial en la determinación de la jornada.

2.2 Posibles ventajas para el trabajador y su necesaria protección.

2.2.1 Igualdad y proporcionalidad en el tiempo parcial.

2.2.2 No discriminación por razón de sexo en el tiempo parcial.

2.2.3 La relación entre la regla de la proporcionalidad y la discriminación indirecta.

3. La voluntariedad en la contratación a tiempo parcial.

3.1 Voluntariedad en la contratación inicial.

\subsection{Voluntariedad en la transformación del contrato.}

3.2.1 La conversión como fórmula para evitar un despido colectivo.

3.2.2 La conversión y el despido objetivo individual.

3.2.3 Reducción de jornada por causas empresariales y tiempo parcial.

3.2.3.1. La reducción de jornada como modificación sustancial del contrato.

\subsubsection{La reducción temporal de jornada ex art. 47 ET.}

4. Conclusión: El necesario cambio de rumbo legislativo.

Bibliografía 


\section{Introducción}

El contrato a tiempo parcial se configura como un instrumento muy versátil para las empresas y los trabajadores a la hora de determinar y distribuir el tiempo dedicado al trabajo.

Efectivamente, del lado empresarial permite racionalizar el uso del tiempo de trabajo en función de las necesidades de la empresa y con ello mejorar su eficiencia y competitividad. Por otro lado, los trabajadores pueden utilizarlo como un instrumento de conciliación en cuanto que posibilita compatibilizar la vida laboral con la formación y la vida familiar, ampliar el tiempo de ocio o combinar varios empleos con unos márgenes de seguridad adecuados.

Las demandas de flexibilidad interna ya no son exclusivas del empresario y diseñan un damero maldito en el que se contrapone una "flexibilidad empresarial para atender las necesidades sobrevenidas de cambio productivo u organizativo, frente a la flexibilidad opuesta de los trabajadores para poder atender inesperadas y también sobrevenidas obligaciones de atención familiar" ${ }^{\text {, }}$ lo que requiere que la adaptabilidad del tiempo de trabajo haya de ser bidireccional ${ }^{3}$. En general, se contrapone un modelo regulador basado en la flexibilidad y en la desregulación normativa que permita al empresario mayores espacios de actuación, frente a un modelo más imperativo que pretende cierta seguridad jurídica al dotar de derechos y prerrogativas a los trabajadores que limiten la precarización de sus condiciones de trabajo y permitan la conciliación laboral y familiar. Estos modelos determinan que las actuaciones legislativas priorizando algunas de estas demandas tengan un efecto negativo sobre las otras, sin que las propias demandas del legislador - véase la DA 29, de Ley 27/2011, de 1 de agosto, sobre actualización, adecuación y modernización del sistema de Seguridad Social-, para alcanzar una reforma negociada que intente mediar entre estos intereses hayan surtido efecto ${ }^{4}$.

En cualquier caso, hoy por hoy, esta modalidad contractual no resulta adecuada para todas las categorías de trabajadores. Mientras que para los que ocupan puestos de trabajo con altos niveles retributivos puede ser una solución para administrar su tiempo, en el caso contrario, actúa como un factor más de precarización. Además, este tipo de empleo tiene un elevado impacto de género, ya que son las mujeres quienes mayoritariamente desempeñan este tipo de trabajos con una tasa que en la actualidad alcanza el $72 \% 5$. En

\footnotetext{
${ }^{2}$ CRUZ VILLALÓN, J. (2010) La flexibilidad interna en la reforma laboral de 2010, Relaciones Laborales (21).

${ }^{3}$ CASAS BAAMONDE, M. E. (2017), Distribución irregular de la jornada, flexibilidad del tiempo de trabajo y tiempo de vida personal y familiar, Revista Jurídica de la Universidad de León, (4), p. 7.

${ }^{4}$ MARTÍNEZ YAÑEZ, N. M. (2014), Las horas complementarias como instrumento de gestión flexible del contrato de trabajo a tiempo parcial, Temas Laborales, (126), pp. 93 y 94.

${ }^{5}$ Datos EPA del Instituto Nacional de Estadística. De hecho, según se muestra en el Informe CES (2018), Economía, Trabajo y Sociedad. Memoria sobre la situación socioeconómica y laboral. España 2017 [CDROM], Madrid: CES, p. 349, mientras que desde 2014 el empleo a tiempo parcial masculino decrece, el ISSN: 2174-6419 Lex Social, vol. 9, núm. 2 (2019)
} 
buena parte, esta diferencia se vincula al tipo de actividad que se desarrolla mediante estos contratos y la segregación del mercado de trabajo en relación con el empleo femenino. La segregación de género en el empleo parcial está igualmente ligada a la conciliación, ya que los datos demuestran que son las mujeres quienes mayoritariamente utilizan el tiempo parcial para atender a estas necesidades familiares. Efectivamente, según se desprende de la EPA, mientras que sólo un 3\% de los trabajadores lo elije para atender a obligaciones familiares, un $20 \%$ de las mujeres lo hace por estos motivos ${ }^{6}$. No debe extrañar que la doctrina describa el tiempo parcial, de manera contundente, afirmando que "lleva grabado a fuego y sangre el sesgo de la feminización"7.

Este contrato además se ha venido utilizando como un instrumento de regulación del mercado de trabajo con el fin de influir en la tasa de desempleo ${ }^{8}$. Dado que el mercado de trabajo español se caracteriza por un alto nivel de temporalidad y por una baja tasa de actividad, una de las herramientas que puede reducir ambos factores es el recurso al trabajo a tiempo parcial ${ }^{9}$. Es obvio, no obstante, que por sí sólo no elimina las bajas tasas de ocupación ni la temporalidad, lo cual no impide reconocer su capacidad de impacto en ambos elementos ${ }^{10}$.

De hecho, la confianza del legislador en este tipo de contrato para paliar las consecuencias de la última crisis económica sobre el empleo parece haberse visto recompensada, pues durante este tiempo se han creado nuevos empleos a tiempo parcial que compensaban en parte la pérdida de empleo indefinido. Puede decirse que las empresas optaban por jornadas reducidas para compensar la caída de la demanda ${ }^{11}$. De esta manera, mientras

femenino sigue avanzando. Esta situación no es exclusiva de España, sino que es propia de la mayoría de los países europeos. De acuerdo con los estudios a los que se ha tenido acceso, en Europa la tasa de ocupación del empleo a tiempo parcial por parte de las mujeres alcanzaba en 2011 un $80 \%$ -SALLADARRÉ, F.; HLAIMI, S. B. (2014), Las mujeres y el trabajo a tiempo parcial en los países europeos, Revista Internacional del Trabajo, 133(2), p. 325 según datos de OECD. Stats Extracts. Esta situación se mantiene y así en 2016 prácticamente un tercio (31,4\%) de las mujeres de entre 20 y 64 años trabaja a tiempo parcial en la Unión Europea, mientras que la proporción de hombres con empleo parcial es de un 8,2\% -COMISION EUROPEA (2017), Mujeres en el mercado de Trabajo [en línea], Fichas temáticas del Semestre Europeo. Mercados de trabajo y cualificaciones. p. 4. Recuperado de https://ec.europa.eu/info/sites/info/files/file_import/european-semester_thematic-factsheet_labour-forceparticipation-women_es.pdf

${ }^{6}$ Estos datos se han mantenido con ligeras variaciones desde hace años. Las estadísticas del INE ya señalaban en el año 2012 que el empleo parcial de mujeres alcanzaba el 75,4\% y que, tomando como referencia el género, un $24,5 \%$ de los contratos de mujeres eran a tiempo parcial mientras que en el caso de los hombres sólo se llegaba al 6,6\%

${ }^{7}$ CABEZA PEREIRO, J.; LOUSADA AROCHENA, F. (2018), El trabajo a tiempo parcial: algunos comentarios valorativos, Derecho de las Relaciones Laborales, (4), p. 430.

${ }^{8}$ Sobre el uso del contrato a tiempo parcial como política de empleo vid. ESPÍN SÁEZ, M. (2015), El contrato a tiempo parcial: de la oportunidad de generar empleo a la precariedad en el empleo, Revista Jurídica de la Universidad Autónoma de Madrid, 1(31), pp. 144 y ss.; y RUANO ALBERTOS, S. (2017), El contrato a tiempo parcial: las posibles perversiones en su utilización. Revista General de Derecho Del Trabajo y de La Seguridad Social, (46), pp. 1-47

${ }^{9}$ FERRADANS CARAMES, C. (2006), El contrato de trabajo a tiempo parcial. Difícil equilibrio entre flexibilidad y seguridad, Cizur Menor (Navarra), p. 27.

${ }^{10}$ CRUZ VILLALÓN, J., en prólogo a FERRADANS CARAMES (2006), ob. cit., p. 18.

${ }^{11}$ BOTE ÁlVAREZ-CARRASCO, V.; CABEZAS ARES, A. (2012), Conciliación y contrato a tiempo parcial en España: Efectos de la Crisis, Pecvnia, (14), pp. 210 y ss. 
que en el año 2008 los contratos a tiempo parcial suponían un total del $11 \%$ de los contratos, en el año 2016, este porcentaje se elevaba hasta el 16\%, aunque sigue por debajo del $19 \%$ del total europeo ${ }^{12}$.

Sin embargo, la realidad es que, con estas políticas, y pese a los datos ofrecidos, tan sólo se ha conseguido elevar el nivel de precariedad en España. La destrucción del empleo estable y a tiempo completo se ha paliado con el uso de esta modalidad contractual ${ }^{13}$, ganando incluso terreno a la contratación temporal ${ }^{14}$. Además, en demasiadas ocasiones, se ha utilizado para encubrir jornadas ampliadas e incluso completas ${ }^{15}$. En este sentido, se confirma una tendencia en la legislación que altera la función prototípica del ordenamiento jurídico laboral: la tutela del trabajador, asumiendo ahora la de la tutela de la empresa a base de potenciar la creación de empleo, introduciendo modificaciones que pretenden crear las condiciones para que la economía pueda volver a crear empleo y atraiga de nuevo a los mercados e inversores ${ }^{16}$. En esta tesitura, el contrato a tiempo parcial en muchas ocasiones ni siquiera cumple con los estándares de un trabajo decente, constituyendo o potenciando situaciones de violencia en el trabajo.

En las siguientes líneas trataremos de analizar críticamente las ventajas de este contrato para empresarios y trabajadores al tiempo que se subrayan aquellos aspectos que impiden un uso racional del mismo y se proponen propuestas para mejorar su regulación.

\section{El contrato a tiempo parcial: un recurso para la contratación estable y de calidad}

Debe comenzarse resaltando un apunte sobre el propio concepto del tiempo parcial, cuyas consecuencias son ciertamente importantes para las materias a tratar en este estudio. Como es sabido, el art. 12 ET determina que "el contrato de trabajo se entenderá celebrado a tiempo parcial cuando se haya acordado la prestación de servicios durante un número de horas al día, a la semana, al mes o al año, inferior a la jornada de trabajo

\footnotetext{
${ }^{12}$ Estos datos no dan cuenta evidentemente del empleo a tiempo parcial que permanece en la economía sumergida o informal, de lo que cabe deducir que su utilización es mucho mayor -CABEZA PEREIRO, J.; LOUSADA AROCHENA, F. (2018), ob. cit., p. 424.

${ }^{13}$ TASCÓN LÓPEZ, R. (2017), El contrato a tiempo parcial como instrumento de flexibilidad interna quasi absoluta, Documentación Laboral, (111), p. 133. Señala el autor más adelante que "parece que una idea siniestra preside los bienintencionados intentos normativos de favorecer la contratación: que si se permiten ciertas condiciones flexibles y/o precarizadas (y, por tanto, más asequibles para la empresa) habrá mayores posibilidades de incorporación al mercado de trabajo, en una versión de la idea de flexiseguridad, cuando menos, poco afortunada (cfr. p. 135).

${ }^{14}$ PÉREZ DEL PRADO, D. (2014), El trabajo a tiempo parcial: ¿una solución al problema del desempleo?, Revista de Información Laboral, (5), p. 4/9; y RUANO ALBERTOS, S. (2017), ob. cit., p. 44.

${ }^{15}$ Se ha manifestado que el tipo de fraude que ha aumentado más en los últimos tiempos es el de los trabajadores a tiempo parcial que realizan incrementos de jornada por encima del 50\%; y que los sectores más afectados son hostelería y comercio en los que se concentra la mayoría de los contratos a tiempo parcial -Informe anual 2015 de la Inspección de Trabajo. RUANO ALBERTOS, S. (2017), ob. cit., p. 42.

${ }^{16}$ GARCÍA TESTAL, E.; ALTÉS TÁRREGA, J. A. (2015), El uso de las modalidades contractuales como medida de fomento del empleo juvenil y prolongación de la vida laboral [en línea], Revista de Información Laboral, (2). En similar sentido, MIÑARRO YANINI, M. (2014), El contrato a tiempo parcial tras sus últimas reformas: flexibilidad rayana en la distorsión de su esencia, Relaciones Laborales, (3). Recuperado de BD La Ley Digital, Ref. LA LEY 936/2014, p. 3/23; CASAS BAAMONDE, M. E. (2017), ob. cit., p. 12; RUANO ALBERTOS, S. (2017), ob. cit., p. 33.
} 
de un trabajador a tiempo completo comparable". El precepto maneja en la definición un criterio objetivo dando relevancia al acuerdo manifestado en el contrato. Sin embargo, la Directiva 97/81/CE del Consejo de 15 de diciembre de 1997 relativa al Acuerdo marco sobre el trabajo a tiempo parcial concluido por la UNICE, el CEEP y la CES (en adelante, AMTTP), en su Cláusula 3.1, utiliza un criterio subjetivo, poniendo el punto de mira en el trabajador y no en el contrato. Así, señala que "se entenderá por «trabajador a tiempo parcial» a un trabajador asalariado cuya jornada normal de trabajo, calculada sobre una base semanal o como media de un período de empleo de hasta un máximo de un año, tenga una duración inferior a la de un trabajador a tiempo completo comparable" 17 . Esta diferencia de criterio tiene notables consecuencias, al reducir el ámbito de aplicación del tiempo parcial en la norma interna a los supuestos en que este nace como consecuencia de un acuerdo de voluntades, dejando fuera del mismo otras situaciones de jornada de trabajo reducida ${ }^{18}$. Sobre los efectos de esta situación volveremos más adelante en dos ocasiones.

\subsection{Ventajas empresariales: la flexibilidad empresarial en la determinación de la jornada.}

Como se ha señalado anteriormente, la configuración actual de esta modalidad contractual permite unos márgenes de adaptación a la necesidad real de mano de obra muy amplios. Esta cualidad del contrato parcial se proyecta especialmente en el sector terciario de la actividad económica, aunque la afirmación es igualmente extensible a otros sectores de actividad.

Efectivamente, la flexibilidad que se ha introducido mediante las sucesivas reformas de su régimen jurídico ha posibilitado este efecto. El primer cambio importante se produjo ya iniciada la década de los 90 cuando desapareció el límite legal de 2/3 que distinguía el contrato a tiempo parcial del contrato a tiempo completo, entendiéndose a partir de entonces el primero como el que se realiza con una jornada inferior, al día, a la semana, al mes o al año, a la establecida habitualmente para la actividad en que se realice el contrato $^{19}$. Dicho límite se reinstauró en el año 1998, fijándose en el 77\% de la jornada a tiempo completo establecida en convenio o, en su defecto, la máxima legal ${ }^{20}$. Sin embargo, este tope se eliminó definitivamente a comienzos del nuevo milenio, pasando a definirse el contrato a tiempo parcial como el celebrado durante un número de horas, al día, al a semana, al mes o al año, inferior a la jornada de un trabajador a tiempo completo

\footnotetext{
${ }^{17}$ El Convenio 175 OIT sobre el trabajo a tiempo parcial, de 24 de junio de 1994, no ratificado por España, también adopta este criterio subjetivo señalando que "la expresión trabajador a tiempo parcial designa a todo trabajador asalariado cuya actividad laboral tiene una duración normal inferior a la de los trabajadores a tiempo completo en situación comparable".

${ }^{18}$ CABEZA PEREIRO, J.; LOUSADA AROCHENA, F. (2018), ob. cit., p. 424.

${ }^{19}$ Real Decreto-Ley 18/1993, de 3 de diciembre, de medidas urgentes de fomento de la ocupación; y Ley 10/1994, de 19 de mayo, sobre medidas urgentes de fomento de la ocupación.

${ }^{20}$ Real Decreto-Ley 15/1998, de 27 de noviembre, de medidas urgentes para la mejora del mercado de trabajo en relación con el trabajo a tiempo parcial y el fomento de la estabilidad.
} 
comparable ${ }^{21}$. Desde entonces, en teoría basta con que se establezca el contrato con una jornada una hora inferior a la señalada para el contrato a tiempo completo.

Además, las múltiples formas de distribución de la jornada amplían el margen de flexibilidad. Junto con el contrato a tiempo parcial consistente en realizar regularmente una jornada diaria inferior (contrato a tiempo parcial horizontal) conviven otras posibilidades, pues, de acuerdo con el art. 12.1 ET, la prestación de servicios se puede llevar a cabo"durante un número de horas al día, a la semana, al mes o al año, inferior a la jornada de trabajo de un trabajador a tiempo completo comparable", esto es, reduciendo los días de servicio (contrato a tiempo parcial vertical) o combinando ambas posibilidades (distribución mixta) ${ }^{22}$.

Otro ejemplo de la (excesiva) flexibilidad a la que nos referimos es el actual régimen jurídico de las horas complementarias. La ampliación de la jornada ordinaria en el contrato a tiempo parcial siempre ha estado rodeada de polémica y, aun así, se ha utilizado de forma recurrente por el legislador para dar mayor versatilidad a este contrato ${ }^{23}$. En este sentido, el Real Decreto-Ley 3/2012, de 10 de febrero, de medidas urgentes para la reforma del mercado laboral, levanto la tradicional prohibición existente de realizar horas extraordinarias en los contratos a tiempo parcial. Esta anómala situación no tuvo mucho recorrido, ya que el Real Decreto-Ley 16/2013, de 20 de diciembre, de medidas para favorecer la contratación estable y mejorar la empleabilidad de los trabajadores, las volvió a prohibir, si bien introdujo aun mayor flexibilidad y precarización al reformar el régimen de las horas complementarias.

Esta disposición normativa ha procedido a elevar el límite de horas complementarias que pueden pactarse por escrito hasta el 30\% de las horas ordinarias contratadas, al tiempo que permite la negociación colectiva lo amplíe aún más (pero no que lo reduzca) hasta alcanzar el $60 \%$ de las horas ordinarias. Por otro lado, se reduce el plazo de preaviso (de 7 a 3 días) para su realización, permitiendo mayor discrecionalidad en su uso por parte de la empresa. Además, se elimina la preferencia para que dicha ampliación se lleve a cabo preferentemente en un convenio colectivo sectorial. De esta manera, siguiendo la línea marcada en otras reformas de la normativa laboral, se prioriza el convenio colectivo de empresa, sobre el que los empresarios tienen mayor control y poder en la negociación.

Asimismo, se posibilita el pacto de horas complementarias en los contratos temporales a tiempo parcial. De esta manera se precariza todavía más la situación de estos trabajadores, pues, por un lado desaparece el incentivo empresarial para contratar por tiempo indefinido

\footnotetext{
${ }^{21}$ Real Decreto-ley 5/2001, de 2 marzo, de medidas urgentes de reforma del mercado de trabajo para el incremento del empleo y la mejora de su calidad; y Ley 12/2001, de 9 de julio, de medidas urgentes de reforma del mercado de trabajo para el incremento del empleo y la mejora de su calidad.

${ }^{22}$ STS, de 14 de mayo de 2007, Rec. 85/2006.

${ }^{23}$ LOUSADA AROCHENA, J. F. (2014), El trabajo a tiempo parcial en el Real Decreto Ley 16/2013, de 20 de diciembre, Nueva Revista Española de Derecho del Trabajo (162), p. 129; MIÑARRO YANINI, M. (2014), ob. cit.; y PALOMINO SAURINA, P. (2016), Aspectos relevantes de las horas complementarias en el trabajo a tiempo parcial, Nueva Revista Española de Derecho del Trabajo (191), p. 130.
} 
con el fin de recurrir a las horas complementarias ${ }^{24}$, al tiempo que debe tenerse presente que, precisamente por su situación de temporalidad, pueden verse "influidos" en su decisión de pactarlas por la amenaza de la no renovación del contrato ${ }^{25}$.

Sin embargo, la principal novedad ha sido la incorporación de las horas complementarias voluntarias, que cabe ofrecer al trabajador en cualquier momento e independientemente de que se haya realizado un pacto de horas complementarias. Con ello se viene a paliar la prohibición de realización de horas extraordinarias en este tipo de contratos que reinstauró esta reforma ${ }^{26}$. La realización de estas horas es voluntaria para el trabajador, lo que se recalca dejando claro que "la negativa del trabajador a la realización de estas horas no constituirá conducta laboral sancionable” (art. 12.5.f ET). Además, los márgenes que la norma establece para la realización de las horas complementarias son más estrictos, de manera que no puede superar el $15 \%$ de las horas ordinarias objeto de contrato, ampliables al 30\% por la negociación colectiva (art. 12.5.g ET). En ningún caso, por esta vía, se pueda superar el límite legal de trabajo a tiempo parcial (12.4.c ET), es decir equiparar el tiempo de trabajo de estos trabajadores con el de un trabajador a tiempo completo comparable mediante la suma de las horas ordinarias, las complementarias pactadas y las voluntarias. Debe hacerse notar que, al igual que ocurre en relación las horas complementarias pactadas, el convenio asume un papel muy distinto al que debería, pues lejos de ser un agente protector de las condiciones laborales, introduciendo mejoras en las mismas, posibilita una reforma in peius ${ }^{27}$.

Pese a que la eliminación de las horas extraordinarias y la introducción de esta nueva categoría abarata a la empresa el coste del incremento de jornada, el trabajador se ha visto también favorecido al no permitirse una alternativa a su retribución en metálico, lo que desincentiva su uso y permite mayor estabilidad en la jornada ${ }^{28}$.

El régimen jurídico de las horas complementarias permite al empresario optar por contratar como jornada ordinaria sólo las horas mínimas necesarias, siempre y cuando se superen las 10 horas semanales en cómputo anual (art. 12.5.b y g ET) -lo que supone un mínimo freno a la precarización de este contrato, impidiendo desequilibrios exagerados $^{29}$ - y determinar el resto de la jornada mediante las horas complementarias, ya que, estas en su conjunto podrán alcanzar el $45 \%$ de la jornada ordinaria y, si se eleva el límite legal por convenio colectivo, podrían alcanzar hasta el 90\% de la jornada ordinaria. Nos encontramos por tanto ante un tipo de contrato que permite que el

\footnotetext{
24 TASCÓN LÓPEZ, R. (2017), ob. cit., p. 139, quien habla de una “precariedad al cuadrado" para definir a los trabajadores temporales a tiempo parcial.

${ }^{25}$ MIÑARRO YANINI, M. (2014), ob. cit., p. 4/23.

${ }^{26}$ Con este cambio el empresario sale beneficiado ya que se evita el mayor coste laboral y de seguridad social de las horas extraordinarias -MIÑARRO YANINI, M. (2014), ob. cit., p. 4/23; y PALOMINO SAURINA, P. (2016), ob. cit., p. 138.

${ }^{27}$ ESPÍN SÁEZ, M. (2016), ob. cit., p. 12/18.

${ }^{28}$ MIÑARRO YANINI, M. (2014), ob. cit., p. 5/23.

${ }^{29}$ SIRVENT HERNÁNDEZ, N. (2016), El régimen jurídico de la jornada complementaria en el contrato de trabajo a tiempo parcial tras las modificaciones introducidas por el Real Decreto-Ley 16/2013, de 20 de diciembre". Trabajo y Derecho (5), p. 3; y PALOMINO SAURINA, P. (2016), ob. cit., p. 135.

ISSN: 2174-6419

Lex Social, vol. 9, núm. 2 (2019)
} 
trabajador realice una jornada que casi alcanza la que realizan los trabajadores a tiempo completo, pero con un margen empresarial mucho mayor en su concreción, pues si, llegado el momento, tras un periodo de tiempo en que haya aumentado la necesidad de mano de obra y se haya exigido el cumplimiento del pacto de horas complementarias, la actividad disminuye siempre podría volverse atrás y exigir tan sólo la realización de la jornada convenida inicialmente.

En esta situación el trabajador a tiempo parcial se encuentra desprotegido y asume una carga excesivamente onerosa que poco tiene que ver con las ventajas que a priori este tipo contractual ofrece, pues difícilmente este régimen permite compatibilizar trabajos o vida y familiar y trabajo ${ }^{30}$, sin que el perjuicio pueda verse compensado por la posibilidad de renuncia al pacto de horas complementarias, que requiere justificar, con al menos 15 días y siempre que se haya cumplido un año desde su celebración, la atención de las responsabilidades familiares enunciadas en el artículo 37.6; necesidades formativas, siempre que se acredite la incompatibilidad horaria; o incompatibilidad con otro contrato a tiempo parcial.

Esta regulación ha llevado a la doctrina a cuestionar el contrato a tiempo parcial como modalidad contractual y a plantear si en realidad no se está ante una fórmula flexible de organización del contrato de trabajo ${ }^{31}$. Por otro lado, esta flexibilidad acerca su régimen jurídico al del denominado contrato a llamada, entendiendo por éste aquel en el que el empresario determina de forma sobrevenida los momentos de prestación, y aunque existen límites que permiten considerar que aún no se ha alcanzado ese punto - las 10 horas mínimas semanales en cómputo anual de jornada ordinaria que habilitan la realización de horas complementarias; y el derecho del trabajador a conocer a priori los períodos de prestación de servicios, sin que puedan quedar éstos indeterminados o encomendados a una posterior decisión empresarial (art. 12.4.a ET segundo párrafo) ${ }^{32}$-, como se ha hecho notar por la doctrina, las sucesivas reformas parecen haber querido recrear a la española el modelo alemán de los minijobs ${ }^{33}$.

\subsection{Posibles ventajas para el trabajador y su necesaria protección}

Las ventajas para los trabajadores ya se han anunciado en la introducción de este estudio. El contrato a tiempo parcial permite una mayor flexibilidad en el reparto de tiempo entre la vida privada y la vida laboral y también permite distribuir mejor esta última mediante el recurso de la pluriactividad. Se facilita la atención a las responsabilidades familiares y

\footnotetext{
${ }^{30}$ En el mismo sentido, MIÑARRO YANINI, M. (2014), ob. cit., p. 3/23; y ESPÍN SÁEZ, M. (2016), El contrato a tiempo parcial ¿la conciliación en los tiempos de precariedad? [en línea], Revista de Información Laboral, (12). Recuperado de BD Aranzadi Instituciones, Ref. BIB 2017\10563, p. 11/18, en relación con el plazo que posee el empresario para comunicar la realización de las horas complementarias pactadas que establece el art. 12.5.e ET.

${ }^{31}$ ESPÍN SÁEZ, M. (2015), ob. cit., p. 151.

${ }^{32}$ GOERLICH PESET (2001), ob. cit., 20 y ss.

${ }^{33}$ ARUFE VARELA, A. (2012), Los minijobs alemanes. Un estudio de su régimen jurídico, laboral y de Seguridad Social, comparado con el trabajo marginal español, Revista Española de Derecho del Trabajo, (155), pp. 17 y ss.; y TASCÓN LÓPEZ, R. (2017), ob. cit., pp. 136 y 138. 
posibilita compatibilizar varios trabajos, así como realizar estudios u otras actividades formativas.

El contrato a tiempo parcial también ofrece otro tipo de ventajas. Como ciertos autores señalan, en coyunturas de desempleo persistentes es una vía para la reinserción laboral o de abandono progresivo de la vida activa ${ }^{34}$. De esta manera, el contrato a tiempo parcial se incorpora con fuerza al grupo de medidas que potencian la llamada flexiseguridad, que permitiría a los trabajadores acceder al empleo en condiciones favorables para el empresario y progresar hacia un trabajo estable conforme mejoren sus capacidades y la relación laboral adquiera un carácter más permanente ${ }^{35}$. Ciertamente, entre otros motivos, el Real Decreto-Ley 16/2013 justificaba su actuación normativa sobre el contrato parcial, por su capacidad para permitir el ingreso en el mercado de trabajo y de servir de transición hacia el trabajo completo, por lo que el legislador tiene presente esta configuración del contrato $^{36}$. También se defiende su uso como un instrumento para facilitar el alargamiento de la vida laboral, compatibilizando en parte la pensión por jubilación, como en el denominado contrato de relevo ${ }^{37}$.

Estas teóricas ventajas, definidas como ideales o quimeras por parte de la doctrina laboralista ${ }^{38}$, se han visto obstaculizadas por el actual régimen del contrato a tiempo parcial. Efectivamente, como se ha anticipado, las sucesivas reformas han potenciado su uso, haciéndolo atractivo para las empresas, sin detenerse en los intereses de los trabajadores. De similar manera, las reformas en las modalidades contractuales que permiten alargar la vida laboral no han tenido como punto de la vista el denominado envejecimiento activo, sino lograr la pervivencia del sistema a base exclusivamente de endurecer los requisitos de acceso a estas fórmulas de compatibilización de trabajo y jubilación ${ }^{39}$.

En este sentido, la última reforma llevó consigo la llamada a negociación colectiva sectorial y, en su defecto, de ámbito inferior, para que establecieran los "requisitos y especialidades para la conversión de contratos a tiempo completo en contratos a tiempo parcial, cuando ello esté motivado principalmente por razones familiares o formativas". Si bien ello no impide que la negociación colectiva siga cumpliendo con esta función, lo

\footnotetext{
${ }^{34}$ SALLADARRÉ, F.; HLAIMI, S. B. (2014), ob. cit., pp. 326, citando a O’REILLY, J.; BOTHFELD, S. (2002), What happens after working part-time? Integration, maintenance or exclusionary transitions in Britain and Western Germany, Cambridge Journal of Economics, 26 (4), pp. 409-439.

35 Comunicación de la Comisión al Parlamento Europeo, al Consejo, al Comité Económico y Social Europeo y al Comité de las Regiones de 27 de junio de 2007, Hacia los principios comunes de la flexiguridad: más y mejor empleo mediante la flexibilidad y la seguridad, COM(2007) 359 final, p. 19.

${ }^{36}$ Se ha señalado que se trata de "una concepción, sin duda, disfuncional, pues el contrato a tiempo parcial no debe ser una modalidad de acceso a un empleo precario que cubre la necesidad de trabajadores que no disponen de otra forma de acceder al trabajo" — cfr. CASAS BAAMONDE, M. E. (2017), ob. cit., pp. 13 y 14.

${ }^{37}$ GARCÍA TESTAL, E.; ALTÉS TÁRREGA, J. A. (2015), ob. cit.; GARCÍA PIÑEIRO, N. P. (2014), El trabajo a tiempo parcial como prestación de servicios flexible, estable y de calidad, Nueva Revista Española de Derecho del Trabajo, (14), p. 177 y ss.

38 TASCÓN LÓPEZ, R. (2017), ob. cit., pp. 136 y 137.

${ }^{39}$ GARCÍA TESTAL, E.; ALTÉS TÁRREGA, J. A. (2015), ob. cit., pp. 12/19 y ss.

ISSN: $2174-6419$

Lex Social, vol. 9, núm. 2 (2019)
} 
cierto es que la flexibilización y precarización de estos contratos impiden su uso como instrumento de conciliación de la vida laboral o familiar o por motivos formativos. Las reformas en la contratación parcial en España han resultado asimétricas, privilegiando su uso por las empresas y eliminando los obstáculos que limitan su uso, pero no han atendido a las demandas de los trabajadores. Sin embargo, como nos recuerda la doctrina ${ }^{40}$, la misma Directiva 97/81/CE y el AMTTP, que se usa para legitimar esta forma de actuar (cláusula 5.1.a), tiene como objetivo normalizar el trabajo a tiempo parcial y hacerlo atractivo a los trabajadores. Por ello, entre otras motivaciones, el Considerando 11 de la misma expresa la voluntad de las partes sociales firmantes del Acuerdo de eliminar las "discriminaciones en relación con los trabajadores a tiempo parcial y contribuir al desarrollo de las posibilidades de trabajo a tiempo parcial sobre una base aceptable para los empresarios y los trabajadores". De esta manera, la fórmula española, como muy gráficamente se ha expresado, más que flexiseguridad ha ofrecido flexirriesgo ${ }^{41}$.

De lo anterior se desprende que este tipo de trabajador posee condiciones laborales más desfavorables que las que tiene un trabajador a tiempo completo, lo que requiere que nos refiramos a los mecanismos de garantía existentes.

\subsubsection{Igualdad y proporcionalidad en el tiempo parcial}

El AMTTP que contiene tiene como principal objetivo "garantizar la supresión de las discriminaciones contra los trabajadores a tiempo parcial y mejorar la calidad del trabajo a tiempo parciales" (Cláusula $1^{\text {a }}$ ). Con este fin, en la Cláusula 4 se establece que, "por lo que respecta a las condiciones de empleo, no podrá tratarse a los trabajadores a tiempo parcial de una manera menos favorable que a los trabajadores a tiempo completo comparables por el simple motivo de que trabajen a tiempo parcial, a menos que se justifique un trato diferente por razones objetivas". Ahora bien, como excepción, además de la existencia de razones objetivas, se permite la aplicación del principio pro rata temporis cuando resulte adecuado.

La norma española recoge estos postulados es el art. 12.4.d ET, que sanciona este principio de igualdad y reconoce a los trabajadores a tiempo parcial los mismos derechos que los trabajadores a tiempo completo, si bien se aplicará el denominado principio de proporcionalidad, cuando corresponda por su naturaleza, en función del tiempo trabajado. La cuestión, por tanto, radica en valorar si cabe la aplicación de dicho principio y si, efectivamente, la reducción se aplica de forma proporcionada.

La jurisprudencia del TJUE, con base en este principio, ha neutralizado, por ejemplo, determinadas interpretaciones perjudiciales para los trabajadores a tiempo parcial, ha

\footnotetext{
${ }^{40}$ CASAS BAAMONDE, M. E. (2017), ob. cit., p. 12.

${ }^{41}$ TASCÓN LÓPEZ, R. (2017), ob. cit., p. 134, recogiendo la expresión de BLAZQUEZ CUESTA, M.; MORAL CARCEDO, J. (2014), El empleo a tiempo parcial femenino: flexirriesgo en cinco países europeos, Revista Internacional del Trabajo, (2), pp. 299-324.
} 
validado otras en materia de vacaciones ${ }^{42}$, y ha admitido la modulación de ciertos complementos que no retribuyen trabajo efectivo como los establecidos por hijo a cargo ${ }^{43}$.

A nivel interno el Tribunal Supremo también ha tenido oportunidad de pronunciarse sobre la aplicación de este principio, diferenciando entre aquellos derechos que considera indivisibles, y que deben de disfrutarse en condiciones de igualdad con los trabajadores a tiempo completo y los que permiten su división, en cuyo caso se aplican las reglas de la proporcionalidad $^{44}$.

Conforme a ello, se ha aplicado la regla de la proporcionalidad a los salarios y a otros derechos que por su naturaleza sean medibles y se ha exceptuado cuando se trata de derechos que, por su naturaleza indivisible, han de reconocerse en plena igualdad con los trabajadores a jornada completa como las ayudas de escolaridad, las ayudas por cargo de minusválidos, seguros de vida y de accidentes, etc. [STS de 15 de septiembre de 2006, Rec. $103 / 2005]^{45}$.

El criterio de la divisibilidad del derecho y su disfrute proporcional ha sido tenido en cuenta en muchas ocasiones, tanto en relación con retribuciones salariales ${ }^{46}$, como extrasalariales $^{47}$. De hecho, el Tribunal Supremo entiende que esta regla resulta de aplicación imperativa siempre que sea posible, independientemente de que dicha previsión se haya establecido o no en la norma aplicada. En la STS de 15 de septiembre de 2006, Rec. 103/2005 se razona que "es claro que este precepto acude en primer lugar al principio de igualdad, que deriva del art. 14 de la CE, pero a renglón seguido, habida cuenta de la diferencia de situación en que se encuentran unos y otros trabajadores (a tiempo completo y a tiempo parcial) matiza el principio de igualdad haciendo una

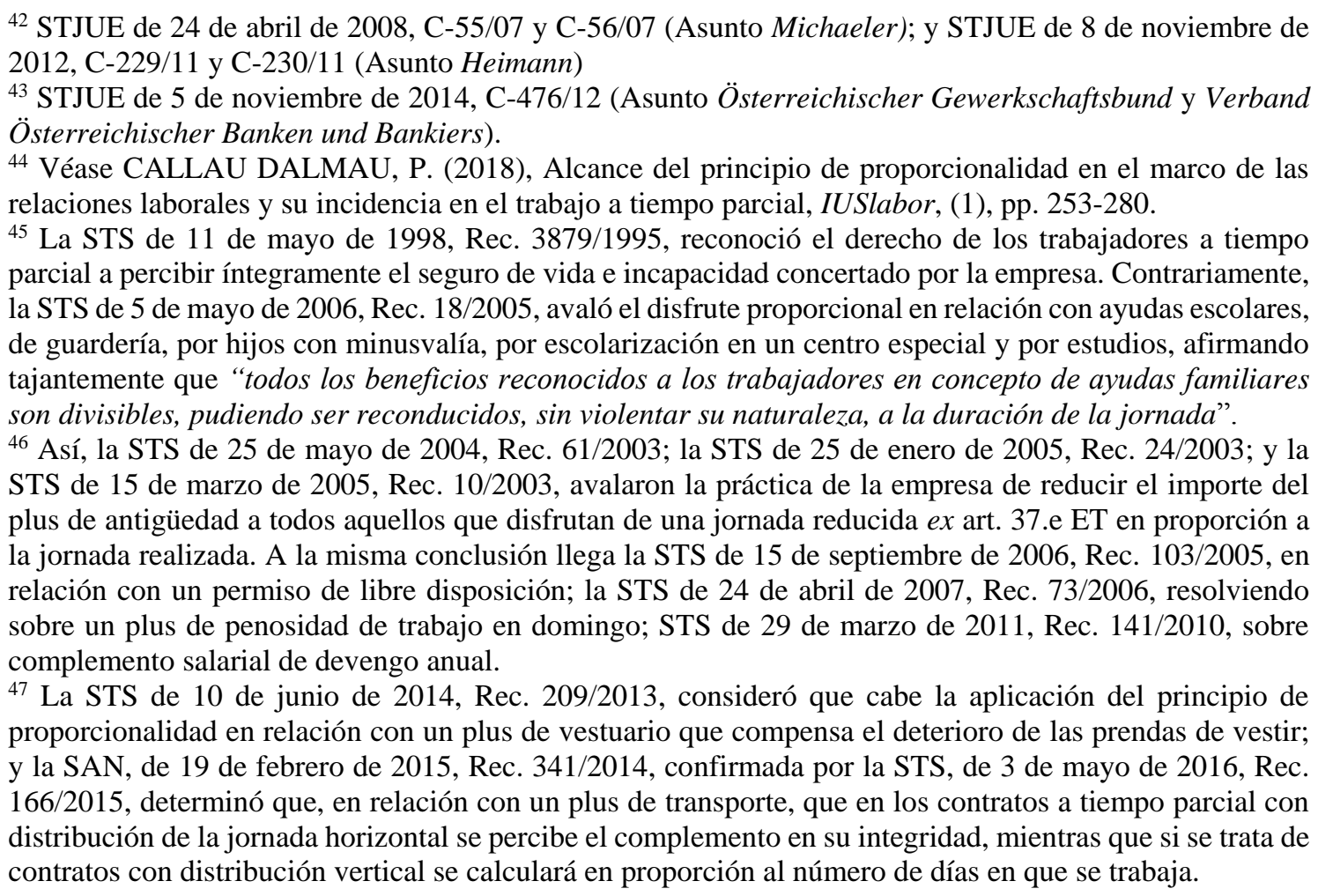
ISSN: 2174-6419 Lex Social, vol. 9, núm. 2 (2019) 
diferenciación razonable, esto es, acudiendo al principio de proporcionalidad cuando así corresponda a la naturaleza de los derechos aplicables, y lo hace de forma imperativa, por lo que la regla general aplicable a los trabajadores a tiempo parcial, no es ya la de la igualdad de derechos pura y simple, sino la de acomodar el disfrute de aquellos derechos que no se consideran divisibles a la proporcionalidad derivada de la situación desigual en que se encuentran, lo cual supone aplicar en plenitud a esta clase de trabajadores aquellos derechos que por su naturaleza sean indivisibles y, en cambio, reconocérselos sólo proporcionalmente cuando el beneficio es susceptible de algún tipo de medición". De acuerdo con este razonamiento corrigió la doctrina judicial que entendía que los trabajadores a tiempo parcial tienen derecho a disfrutar de los permisos por asuntos propios en las mismas condiciones que los trabajadores a tiempo completo, salvo previsión en contrario en el convenio colectivo aplicable [STSJ Cataluña de 15 de abril de 2005, Rec. 3/2005], obviando el hecho de que la negociación colectiva no hubiera establecido ninguna regla al respecto y afirmando que "la finalidad de este beneficio es la de facilitar a los trabajadores, que tienen ocupado todos los días laborables con la jornada de trabajo, tiempo para gestiones personales que no puedan efectuarse durante el descanso semanal, con lo que ya se comprende la situación más favorable que a este respecto tienen los trabajadores a tiempo parcial que sólo trabajan los fines de semana".

La doctrina ha hecho notar que el criterio de la proporcionalidad conlleva en muchas ocasiones a situaciones de clara desventaja, por cuanto se convierten en una doble penalización para estos trabajadores ${ }^{48}$. Por ello coincido cuando proponen dotar de mayor seguridad jurídica al régimen de protección del trabajador a tiempo parcial mediante la presunción de la igualdad, de manera que ésta sólo decaería cuando se establezca expresamente la regla de proporcionalidad y siempre que fuera objetivamente justificable. Además, sería necesario complementar la aplicación de la igualdad con otros derechos específicos para este tipo de trabajadores que permitan mayor control sobre su tiempo de trabajo y que posibiliten aumentar o disminuir su jornada, con el fin de lograr un contrato a tiempo parcial "sobre unas bases voluntarias" 49 .

\subsubsection{No discriminación por razón de sexo en el tiempo parcial.}

Junto con la equiparación de los trabajadores a tiempo completo y a tiempo parcial, en la protección de estos últimos también tiene una incidencia muy importante la consecución del principio de igualdad y no discriminación por razón de sexo. Efectivamente, como ha recordado la doctrina, la Cláusula 4 AMTTP garantiza tanto la no discriminación de los trabajadores a tiempo parcial y a tiempo completo, como la no discriminación del trabajo femenino que presta servicios bajo esta modalidad contractual ${ }^{50}$. La normativa española, muy recientemente ha corroborado esta garantía, mediante la adición al art. 12.4.d ET, junto con el principio de igualdad de trato, de la necesidad de garantizar "en todo caso la

\footnotetext{
${ }^{48}$ Así lo señalan CABEZA PEREIRO, J.; LOUSADA AROCHENA, F. (2018), ob. cit., p. 429, en relación con las reglas convencionales sobre el complemento de antigüedad.

${ }^{49}$ CABEZA PEREIRO, J.; LOUSADA AROCHENA, F. (2018), ob. cit., p. 429.

${ }^{50}$ SIERRA HERNAIZ, E.; GOÑI SEIN, J. L. (2014), ob. cit., p. 5/15.
} 
ausencia de discriminación, tanto directa como indirecta, entre mujeres y hombres" (art. 2.4 Real Decreto-ley 6/2019, de 1 de marzo, de medidas urgentes para garantía de la igualdad de trato y de oportunidades entre mujeres y hombres en el empleo y la ocupación).

A priori, el contrato de trabajo a tiempo parcial puede funcionar como un instrumento que posibilite la incorporación de las mujeres al empleo, sobre todo cuando el tiempo completo es prácticamente una utopía, dada la necesidad de conciliar trabajo y necesidades familiares. Los poderes públicos posibilitan la participación de la mujer en el mercado de trabajo en función de factores como el "tamaño del sector púbico, la política familiar, la política fiscal los derechos de maternidad y las posibilidades de guardería" "51. Pues bien, dentro de estas medidas, la adopción de formas de trabajo flexible ha sido uno de los recursos contemplados para facilitar la conciliación laboral. Lo que ocurre es que, pese a que formalmente se ofrece en condiciones de igualdad, finalmente existen diferencias notables en su utilización entre sexos, edades y ocupaciones. Esta asimetría también se explica por la propia preferencia de las mujeres por horarios laborales más cortos y por la dificultad que tienen para negociar cuando el empleo se confronta con las responsabilidades familiares ${ }^{52}$. Así, en la práctica nos encontramos ante un contrato fuertemente feminizado, que conlleva altas dosis de precariedad laboral entre el sexo femenino y que aumenta notablemente las posibilidades de la exclusión de la mujer del mercado de trabajo e incluso el riesgo de pobreza y exclusión social, por la imposibilidad de consolidar una pensión digna y la dependencia de otras rentas familiares ${ }^{53}$. Por otra parte, esta estigmatización coadyuva a perpetuar los roles de género de hombre y mujeres, lo que pone en entredicho las posibles ventajas de este tipo de contratación, aún en los casos en que se elige de forma voluntaria ${ }^{54}$. De esta manera, debería tenerse presente por parte de los poderes públicos que cualquier actuación sobre el mismo debe ser medida en términos de género.

\footnotetext{
${ }^{51}$ SALLADARRÉ, F.; HLAIMI, S. B. (2014), ob. cit., p. 326

52 Ibidem, p. 326.

${ }^{53}$ BOTE ÁlVAREZ-CARRASCO, V.; CABEZAS ARES, A. destacan que las políticas de conciliación "ayudan a mejorar la flexibilidad y competitividad de la economía mejorando la calidad de vida de los miembros de la sociedad, reducen los costes de oportunidad de las decisiones de maternidad y garantizan la sostenibilidad a largo plazo del sistema de bienestar" [(2012), Conciliación y contrato a tiempo parcial en España: Efectos de la Crisis, Pecvnia, (14), p. 208 y 209]. En otros estudios se han alcanzado conclusiones similares. Así, en SALLADARRÉ, F.; HLAIMI, S. B. (2014), ob. cit., pp. 340 y 341, se pone de manifiesto que "la tasa de pobreza entre los trabajadores a tiempo parcial es por término medio más elevada que entre los trabajadores a tiempo completo en la mayoría de los países observados. Las trabajadoras a tiempo parcial breve podrían, pues, enfrentarse a condiciones económicas todavía más difíciles. En investigaciones posteriores habría que realizar una comparación entre los ingresos de los dos tipos de tiempo parcial. El análisis podría efectuarse al nivel de los hogares, para tener en cuenta otros posibles ingresos de la familia. Para las mujeres que viven en pareja, el papel y el ingreso del cónyuge o compañero pueden influir mucho en sus condiciones de vida y en las decisiones adoptadas en el seno del hogar".

${ }^{54}$ En similar sentido SIERRA HERNAIZ, E.; GOÑI SEIN, J. L. (2014), El empleo a tiempo parcial desde la perspectiva de género [en línea], Revista de Derecho Social, (28). Recuperado de BD Tirant on Line, Ref. TOL599.845, ob. cit., p. 2/15. Especialmente recomendable es el estudio sobre la situación sociolaboral de la mujer en relación con el contrato a tiempo parcial que realizan los autores (pp. 2/15 a 4/15).
} 
Pues bien, fuera de los casos en que la diferencia de trato sea evidente y pueda venir amparada en razones objetivas, en relación con este tipo de discriminación cobra especialmente importancia, como instrumento para valorar la existencia de una desigualdad prohibida, la denominada discriminación indirecta. Como es sabido, este concepto de origen norteamericano prohíbe tanto las discriminaciones abiertas, como las que, bajo la apariencia de prácticas aparentemente neutras o formalmente justas, en la práctica resultan discriminatorias ${ }^{55}$. La normativa europea recoge este concepto, en la Directiva 2006/54/CE del Parlamento Europeo y del Consejo, de 5 de julio de 2006 , relativa a la aplicación del principio de igualdad de oportunidades e igualdad de trato entre hombres y mujeres en asuntos de empleo y ocupación (refundición), como "la situación en que una disposición, criterio o práctica aparentemente neutros sitúan a personas de un sexo determinado en desventaja particular con respecto a personas del otro sexo, salvo que dicha disposición, criterio o práctica pueda justificarse objetivamente con una finalidad legítima y que los medios para alcanzar dicha finalidad sean adecuados y necesarios" "56. En España el Tribunal Constitucional se sirvió de este concepto para resolver sobre la existencia de una discriminación en materia salarial STC 145/1991, de 1 de julio, y también en relación con la equiparación entre trabajadores a tiempo completo y a tiempo parcial $^{57}$. Por su parte, la normativa española se refirió por primera vez a la discriminación indirecta, sin definirla, en el art. 4.2.c ET, desde su modificación por la Ley 62/2003, de 30 de diciembre, de medidas fiscales, administrativas y del orden social. El proceso de incorporación a nuestro ordenamiento se culminó con la Ley Orgánica 3/2007, de 22 de marzo, para la igualdad efectiva de mujeres y hombres, cuyo art. 6, definió la discriminación indirecta en similares términos a los de la Directiva.

En relación con la protección del trabajador a tiempo parcial la prueba estadística que confirma una discriminación indirecta ha servido al TJUE para invalidar algunas

\footnotetext{
55 Se trata de una construcción judicial (disparate impact) que apareció por primera vez en la sentencia del Tribunal Supremo norteamericano Griggs v. Duke Power Company, 401, US 424, 1971.

${ }^{56} \mathrm{La}$ discriminación indirecta ya fue recogida, aun sin definición, en la Directiva 76/207/CEE, sobre igualdad de trato entre hombres y mujeres. Posteriormente se delimitó dicho concepto en la ya derogada Directiva 2002/73/CE del Parlamento Europeo y del Consejo, de 23 de septiembre de 2002, que modifica la Directiva 76/207/CEE del Consejo relativa a la aplicación del principio de igualdad de trato entre hombres y mujeres en lo que se refiere al acceso al empleo, a la formación y a la promoción profesionales, y a las condiciones de trabajo.

${ }^{57}$ STC 22/1994, de 27 de enero, que toma como referencia la jurisprudencia comunitaria que entendía como discriminación indirecta la exclusión de ciertas ventajas laborales a los trabajadores tiempo parcial, toda vez que se constata que este colectivo está formado básicamente por trabajadores de sexo femenino y no existe una razón justificación objetiva que ampare la diferencia de trato. Se trata de las STJCE de 13 de mayo de 1986, C-170/84 (Asunto Bilka Kaufhaus); STCE de 13 de julio de 1989, C-171/88 (Asunto Rinner v. Kühn); STJCE de 13 de diciembre de 1989, C-102/88 (Asunto Ruzius v. Wilbrink); STJCE de 27 de junio de 1990, C-33/89 (Asunto María Kowalska) STJCE de 6 de febrero, C-457/93(Asunto Lewark); y STJCE 7 de marzo de 1996, C-278/93 (Asunto Speckmann). En otras sentencias el Tribunal europeo ha justificado de diferencias de trato en relación con los trabajadores a tiempo parcial, pese al impacto de género, al entender que se da una justificación objetiva - STJUE de 26 de septiembre de 2000, C-333/98 (Asunto Kachelmann); y STJUE de 6 de abril de 2000, C-226/98 (Asunto Jorgensen) - , lo que ha llevado a la doctrina a criticar los resultados un tanto aleatorios de la opción ponderativa del Tribunal —SIERRA HERNAIZ, E.; GOÑI SEIN, J. L. (2014), ob. cit., p. 5/15.
} 
condiciones de trabajo que determinaban que los trabajadores con estos contratos recibieran una retribución menor aunque realizaran una jornada $\operatorname{similar}^{58}$, pero, sin duda, donde mayor incidencia ha tenido ha sido en el plano de la protección social de los trabajadores.

Efectivamente, uno de los mayores problemas que plantea la parcialidad tiene que ver con la protección que dispensa el sistema público de seguridad social. Podría decirse que el sistema de protección, pensado para el trabajador a tiempo completo, no ha sabido mediar entre el principio de contributividad propio del sistema de seguridad social y el de proporcionalidad e igualdad de trato con los trabajadores a tiempo completo y, sobre todo, con el de no discriminación por razón de género que dispensa la normativa laboral a estos trabajadores.

En un principio, la protección social de los trabajadores se sustentó en base a aplicación del principio de proporcionalidad de forma absoluta, tanto en materia de cotización, como de protección $^{59}$. Pues bien, aunque la cotización parcial no penaliza el régimen contributivo de los trabajadores a tiempo parcial, evitando que se cotice en función de las bases de los trabajadores a tiempo completo, dificulta su carrera asegurativa y el acceso a las prestaciones, al hacer más difícil lograr los periodos de carencia para causarlas y minorar sus bases reguladoras ${ }^{60}$. Ello llevó a la jurisprudencia a dulcificar este sistema, interpretando que, al margen de la duración de la jornada diaria, debía computarse un día cotizado por cada día trabajado (STS de 26 de mayo de 1993, Rec. 2739/1992). La normativa, sin embargo, se mantuvo firme en la aplicación del criterio de proporcionalidad estricta $^{61}$, hasta que el Real Decreto-ley 15/1998, de 27 de noviembre, de medidas urgentes para la mejora del mercado de trabajo en relación con el trabajo a tiempo parcial y el fomento de su estabilidad, introdujo unas mínimas correcciones en relación con el acceso a la jubilación y la incapacidad permanente, mediante la introducción de los "días teóricos de cotización", que resultan de dividir las horas totales trabajadas entre 5, y aplicar a dichos días un coeficiente multiplicador de 1,5.

Pues bien, esta normativa fue objeto de revisión por parte del Tribunal de Justicia de la Unión Europea, sobre la base del principio de no discriminación por razón de género. Efectivamente, la STJUE de 22 de noviembre de 2012, C-385/2011 (Asunto Elbal Moreno $)^{62}$, contestando a una cuestión prejudicial de un Juzgado Social de Barcelona en relación con la denegación de una prestación de jubilación a una trabajadora a tiempo

\footnotetext{
${ }^{58}$ La discriminación por razón de sexo sostuvo la decisión de la STJUE de 31 de marzo de 1981, C-96/80; la STJUE de 13 de mayo de 1986, C-170/84; y sobre todo la STJUE de 6 de diciembre de 2007, C-300/06 (Asunto $V o \beta$ ).

${ }^{59}$ Sobre el tema ROQUETA BUJ, R. (2002), La protección social de los trabajadores a tiempo parcial, Madrid: CES, pp. 53 y ss.

${ }^{60}$ SALA FFRANCO, T.; ROQUETA BUJ, R. (2018), Propuestas para un debate sobre la reforma del contrato a tiempo parcial, Derecho de las Relaciones Laborales, (4), pp. 415 y 416.

${ }^{61}$ Real Decreto 2319/1993, de 29 de diciembre, sobre revalorización de pensiones del sistema de la Seguridad Social y de otras prestaciones de protección social pública para 1994; y Ley 10/1994, de 19 de mayo, sobre medidas urgentes de fomento de la ocupación.

${ }^{62}$ STJUE de 10 de junio de 2010, C-395 y 396/08 (Asunto Bruno y Pettini). 
parcial, al no alcanzar el periodo mínimo de carencia -ya que los 18 años cotizados computaban como menos de 3 años- determinó que la regulación española, "que exige a los trabajadores a tiempo parcial, en su inmensa mayoría mujeres, en comparación con los trabajadores a tiempo completo, un período de cotización proporcionalmente mayor para acceder, en su caso, a una pensión de jubilación contributiva en cuantía proporcionalmente reducida a la parcialidad de su jornada", se opone al art. 4.1 de la Directiva 79/7/CEE del Consejo, de 19 de diciembre de 1978, relativa a la aplicación progresiva del principio de igualdad de trato entre hombres y mujeres en materia de seguridad social. Esta resolución llevó al Tribunal Constitucional, en su sentencia $61 / 2013$, de 14 de marzo, a declarar inconstitucional la DA $7^{\mathrm{a}}$, apartado $1^{\mathrm{o}}$, regla $2^{\mathrm{a}}$ de la entonces vigente LGSS y a que el legislador cambiara el régimen jurídico en esta materia.

Así, la Ley 1/2014, de 28 de febrero, para la protección de los trabajadores a tiempo parcial y otras medidas urgentes en el orden económico y social ${ }^{63}$ dio una nueva redacción a la DA declarada inconstitucional (recogida actualmente en los arts. 247 y 248 LGSS, introduciendo, entre otras medidas, dos factores de corrección al principio de proporcionalidad: el cociente de parcialidad y el cociente global de parcialidad, mediante los que se flexibiliza el número de años necesarios para que los trabajadores a tiempo parcial accedan a las prestaciones de jubilación, incapacidad permanente, muerte y supervivencia, incapacidad temporal, maternidad y paternidad. Estos coeficientes permiten individualizar la situación de cada trabajador, de manera que, "es cada carrera de cotización la que a su vez personaliza el periodo de carencia exigible para acceder a cada prestación" ${ }^{64}$. Con ello, se facilita el acceso a prestaciones, en especial a la de jubilación, si bien la misma puede resultar con una cuantía mínima, lo que obliga a introducir medidas de carácter asistencial como los complementos a mínimos.

Como se ha señalado, la introducción de estos coeficientes, junto con el mantenimiento del coeficiente de corrección del 1,5 para incrementar el número de días cotizados en las pensiones de jubilación y de incapacidad permanente, así como el resto de reglas que se han establecido para integrar lagunas o en materia de complementos mínimos, permiten eludir la tacha de inconstitucionalidad en relación con los periodos mínimos de carencia ${ }^{65}$, pero no acaba de cerrar el problema de la doble proporcionalidad en relación con la

\footnotetext{
${ }^{63}$ Esta ley convalidó el Real Decreto-ley 11/2013, de 2 de agosto, para la protección de los trabajadores a tiempo parcial y otras medidas urgentes en el orden económico y social.

${ }^{64}$ Cfr. ESPÍN SÁEZ, M. (2016), ob. cit., p. 16/18.

${ }^{65}$ ÁLVAREZ CUESTA, H. (2018), Discriminación indirecta en el desempleo en el contrato a tiempo parcial «vertical» en España. Asunto «Espadas Recio» [en línea], Revista Aranzadi Unión Europea, (2), p. 3/17; RODRÍGUEZ CARDO, I. A. (2018), Igualdad y no discriminación en el trabajo a tiempo parcial: la pertinencia de la perspectiva de género y de la prueba estadística, Derecho de las Relaciones Laborales, (2), pp. 164.; ESPÍN SÁEZ, M. (2016), ob. cit., p. 18/18.
} 
cuantía de la pensión ${ }^{66}$, al tiempo que abre nuevas incógnitas sobre la suficiencia de las prestaciones y la sostenibilidad del sistema ${ }^{67}$.

Sin embargo, la doctrina del TJUE no ha sido tan contundente en relación con el cálculo de las prestaciones de los trabajadores a tiempo parcial. La STJUE de 14 de abril de 2015 C 527/13 (Asunto Cachaldora Fernández), entendió, en el caso de una trabajadora a tiempo parcial que solicitaba una pensión por incapacidad permanente, con importantes lagunas de cotización para el cálculo de la base reguladora, que la normativa española vigente para integrar dichas lagunas en los contratos a tiempo parcial no es discriminatoria.

La siguiente corrección normativa en materia de protección social de los trabajadores a tiempo parcial vino dada por la STJUE de 9 de noviembre de 2017, C-98/15 (Asunto Espadas Recio) que apreció discriminación en la manera en que se computa la cotización a efectos de la prestación de desempleo ${ }^{68}$, no ya en comparación con los trabajadores a tiempo completo sino entre los propios trabajadores a tiempo parcial. Efectivamente, la fórmula que utiliza nuestra normativa consistente en computar como día cotizado cualquier día trabajado, independientemente de las horas realizadas (Real Decreto 625/1985, de 2 de abril, por el que se desarrolla la Ley 31/1984, de 2 de agosto, de Protección por Desempleo), beneficia a los trabajadores a tiempo parcial horizontales, esto es, aquellos que trabajan todos los días con una jornada reducida, pero perjudica notablemente a los trabajadores a tiempo parcial vertical, que concentran sus jornadas en determinados días, mientras que en otros no trabajan. De esta manera, las mismas horas de trabajo, en función de su distribución, pueden dar lugar a periodos de cotización muy distintos y, dado que los contratos a tiempo parcial verticales están ocupados mayoritariamente por mujeres, se aprecia que la normativa es discriminatoria ${ }^{69}$. En consecuencia, el RD 950/2018, de 27 de julio, por el que se modifica el Real Decreto 625/1985, de 2 de abril, por el que se desarrolla la Ley 31/1984, de 2 de agosto, de protección por desempleo, ha procedido a cambiar el régimen jurídico, de manera que "se computará el período durante el que el trabajador haya permanecido en alta con

\footnotetext{
${ }^{66}$ GONZÁLEZ DEL REY RODRÍGUEZ, I. (2015), Ley General de Seguridad Social y trabajo a tiempo parcial: Sentencia TC 253/2004, de 22 de diciembre, en GARCÍA MURCIA, J. (Dir.), El control de constitucionalidad de las normas laborales y de Seguridad Social, Cizur Menor (Navarra): Thomson Reuters Aranzadi, pp. 369-370; y RODRÍGUEZ CARDO, I. A. (2018), ob. cit., p. 64

${ }^{67}$ ESPÍN SÁEZ, M. (2016), ob. cit., p. 18/18. Señala la autora que "se vincula el destino de las pensiones de jubilación de los trabajadores a tiempo parcial al propio de los trabajadores a tiempo completo y, con ello, a la cuestión de la suficiencia de dichas prestaciones, cuya cuantía va a sufrir los efectos de la aplicación de fórmulas matemáticas como el factor de sostenibilidad o el índice de revalorización, que generan tanta inseguridad jurídica como dudas sobre el mantenimiento del poder adquisitivo de los futuros pensionistas". SALA FRANCO, T.; ROQUETA BUJ, R. (2018), ob. cit., p. 419, también hacen notar la potencial inviabilidad económica de algunas medidas, como la aplicación de los complementos por mínimos al contrato a tiempo parcial.

${ }^{68}$ En general, sobre las distorsiones de la normativa sobre protección por desempleo en relación con el contrato a tiempo parcial vid. SALA FRANCO, T.; ROQUETA BUJ, R. (2018), ob. cit., pp. 420 y ss.

${ }^{69}$ Sobre esta sentencia y sus consecuencias ÁLVAREZ CUESTA, H. (2018), ob. cit., 8/17 y ss.

ISSN: 2174-6419

Lex Social, vol. 9, núm. 2 (2019)
} 
independencia de que se hayan trabajado todos los días laborables o solo parte de los mismos, y ello, cualquiera que haya sido la duración de la jornada".

Si bien queda claro que no se puede aplicar un principio de proporcionalidad estricto que condenaría a estos trabajadores a la infraprotección, la aplicación del "principio de la diferencia", sin proporcionalidad alguna, también ha sido objetada por parte de la doctrina, pues este trato más favorable puede provocar un agravio comparativo con otros grupos de trabajadores en situación de desventaja como los trabajadores temporales o los parados sin protección contributiva), además de incentivar el fraude ${ }^{70}$.

\subsubsection{La relación entre la regla de la proporcionalidad y la discriminación indirecta}

La doctrina ha mostrado preocupación por lo que considera una excesiva utilización de la discriminación indirecta como elemento de protección del trabajador a tiempo parcial ${ }^{71}$.

En este sentido, en primer lugar, se critica la utilización de datos estadísticos como medio de prueba, pues confiere al juez facultades ilimitadas en orden a su consideración, lo que conlleva cierta dosis de inseguridad jurídica ${ }^{72}$. Y, en segundo lugar, el hecho de que se impongan a otros criterios de mayor trascendencia y precisión técnica jurídica, como ocurre, en relación con la contratación a tiempo parcial, con el principio de proporcionalidad.

De esta manera, se defiende que la utilización de datos estadísticos exógenos que valoran determinadas circunstancias en un determinado entorno socio-laboral de carácter global tienen utilidad para valorar la posible discriminación que puede derivarse de la aplicación de una norma de carácter general, pero no pueden ser decisivos en la valoración de una conducta empresarial particular, cuando se demuestre, mediante datos endógenos, que en dicho ámbito no se concreta la realidad de la estadística. Además, se argumenta que la utilización de la prueba estadística en la discriminación indirecta por razón de sexo debería ser un argumento de refuerzo que no suplantara el juicio de proporcionalidad en la comparación con el trabajador a tiempo completo en la línea de las STC 253/2004, de 22 de diciembre y la STC 50/2005, de 14 de marzo, pues ambas determinan que el principio de igualdad en la ley se vulnera desde la perspectiva del juicio de proporcionalidad, aunque también tienen en cuenta la discriminación indirecta por razón de sexo. Por tanto, se infiere que, "a partir de estas sentencias puede llegarse a la cabal conclusión de que el TC habría reconocido igualmente el amparo si el perjudicado fuera

\footnotetext{
${ }^{70}$ SALA FRANCO, T.; ROQUETA BUJ, R. (2018), ob. cit., p. 416.

${ }^{71}$ RODRÍGUEZ CARDO, I. A. (2018), ob. cit., pp. 163 y ss.

${ }^{72} \mathrm{El}$ autor señala que se utilizan indistintamente datos exógenos y exógenos, relativos a la propia empresa, cuya naturaleza y repercusión no puede equipararse; la necesidad de tener en cuenta el origen y el método seguido en la estadística; la ausencia de umbrales que determinen cuando estamos ante un impacto desproporcionado sobre el colectivo discriminado. De ello se infiere que en el análisis de la existencia de una discriminación indirecta "las reglas de la sana crítica ganan demasiado protagonismo en ausencia de verdaderas pruebas sobre los hechos" - Cfr. Ibídem, p. 167 y 168.
} 
un hombre, pues las reglas legales no habrían implementado correctamente el principio de proporcionalidad"73.

Sin embargo, en otras muchas ocasiones esta doble consideración desaparece y la jurisprudencia ahonda exclusivamente en el argumento de la discriminación indirecta. Así ocurre en la STJUE de 6 de diciembre de 2007, C-300/06 (Asunto Vo $\beta$ ), para determinar que la jornada de un trabajador a tiempo parcial que resulta equivalente a la de un trabajador a tiempo completo por la realización de horas extraordinarias no puede obtener una menor retribución por el valor menor de las horas extraordinarias. Otro tanto se puede decir de algunas de las sentencias recaídas en materia de protección social, como la crucial STJUE de 22 de noviembre de 2012, C-385/2011 (Asunto Elbal Moreno).

De ello se colige que "la diferencia de trato parece resultar intolerable únicamente si propicia una discriminación indirecta -o en su caso directa- por razón de sexo"74, cuando ciertamente, difícilmente se hubiera llegado a otra conclusión si se hubiera invocado el principio de igualdad con los trabajadores a tiempo completo. Además, si el proceso se dirime exclusivamente en torno a la discriminación por razón de sexo, la decisión del Tribunal puede quedar constreñida a validar la situación, en caso de que las pruebas estadísticas resulten rechazadas, como ocurre en la STJUE de 14 de abril de 2015, C-527/13 (Asunto Calchadora Fernandez) ${ }^{75}$, si bien es cierto que, en este caso, previamente el Tribunal considera que la normativa española no se opone al Derecho Europeo y a partir de ahí analiza la existencia de una discriminación indirecta.

Por ello, se defiende constreñir el uso de la prueba estadística a aquellos casos en que las pruebas ordinarias o los medios de interpretación tradicionales se muestras ineficiente y eludir su uso en otros casos, evitando que la variable del sexo, adecuada en momento determinado, destierre el elemento determinante a tomar en consideración: la realización de un trabajo reducido, con el consiguiente peligro de impedir, cuando los datos estadísticos demuestren un perjuicio para las mujeres, que los hombres obtengan la tutela antidiscriminatoria ${ }^{76}$.

En mi opinión, la argumentación utilizada tiene cierto sentido, sobre todo en aquellos casos en que los Tribunales para valorar la existencia de una formulación neutra toman en consideración únicamente su aplicación indistinta a hombres y mujeres, aunque ello viene mediatizado por la formulación de la demanda y la limitación que de ello se deriva para el órgano judicial a la hora de valorar el objeto de conflicto. En la aplicación tanto

\footnotetext{
${ }^{73}$ Cfr. RODRÍGUEZ CARDO, I. A. (2018), ob. cit., p. 170.

${ }^{74}$ Ibidem, p. 163.

${ }^{75}$ Un análisis de la decisión del Tribunal en relación con los datos estadísticos en ALONSO FERNÁNDEZ, J. J; DEVESA CARPIO, J. E.; DEVESA CARPIO, M.; DOMÍNGUEZ FABIÁN, I.; ENCINAS GOENECHEA, B.; MENEU GAYA, R. (2015), El Tribunal de Justicia de la Unión Europea no aprecia discriminación en la fórmula de integración de lagunas para los contratos a tiempo parcial [en línea], Revista Aranzadi Unión Europea, (5).

76 SANCHEZ TORRES, E. (2011), La incidencia de la prueba estadística y del "principio de transversalidad" en la adjetivación de la responsabilidad empresarial en materia de igualdad y no discriminación [en línea], Diario La Ley, (7667), p.; y RODRÍGUEZ CARDO, I. A. (2018), ob. cit. p. 171. ISSN: 2174-6419 Lex Social, vol. 9, núm. 2 (2019)
} 
de la normativa europea como en la interna el primer juicio debería versar sobre la posible quiebra de la igualdad que debe existir entre el trabajo tiempo parcial y el trabajo a tiempo completo, de manera que, si se produce una vulneración de dicho principio, el argumento discriminatorio sí tendría sentido como elemento de refuerzo de la decisión.

Sin embargo, en otras situaciones deberá ser el elemento principal en la toma de decisión, pues una disposición que cumpla con dicho principio y se proyecte de forma igualitaria a hombre y mujeres ha de reputarse nula si, en su aplicación, resulta discriminatoria para la mujer.

\section{La voluntariedad en la contratación a tiempo parcial}

Otro eje sobre el que pivota el contrato a tiempo parcial es la voluntariedad. Así, la AMTTP, en su Cláusula $1^{a}$ establece, como objetivo, "facilitar el desarrollo del trabajo a tiempo parcial sobre una base voluntaria y contribuir a la organización flexible del tiempo de trabajo de una manera que tenga en cuenta las necesidades de los empresarios y de los trabajadores". Por tanto, nadie debería estar obligado a trabajar a tiempo parcial.

\subsection{Voluntariedad en la contratación inicial}

Esto es evidente en el momento inicial de la contratación. La construcción equilibrada del régimen del tiempo parcial debería favorecer la consecución de contratos de este tipo. Sin embargo, una amplia mayoría de los trabajadores no desean esta fórmula de contratación, pues viene condicionada por las ofertas empresariales y, todo lo más, la aceptan a la espera de lograr un contrato indefinido y a tiempo completo.

Entre los factores que impiden de facto la elección se encuentra, por un lado, el propio régimen jurídico de la contratación a tiempo parcial, posibilitando una gestión interna quasiabsoluta del tiempo de trabajo, convirtiéndolo en una opción indeseada para el trabajador $^{77}$. Si las condiciones de trabajo que se ofertan resultan muy gravosas, quienes pretenden optar a este contrato voluntariamente lo desecharán y, sin embargo, accederán a él quienes por su situación de necesidad han de soportar la precariedad que conlleva dicho régimen. La situación no es distinta si se contempla desde el lado empresarial. El empresario preferirá contratar a quienes estén dispuestos a pactar un margen de horas complementarias mayor, pudiendo así recurrir a ellas cuando lo necesite en razón de la actividad empresarial, por lo que quienes acuden a este contrato para poder compatibilizar distintas necesidades laborales, educativas, sociales o familiares encontrarán más dificultades para ser contratados mediante esta modalidad, pasando a ocuparla los trabajadores a tiempo parcial involuntarios, es decir, aquellos que buscaban un empleo a tiempo completo que no han conseguido ${ }^{78}$.

Por otro lado, también influye la propia coyuntura del mercado de trabajo. En situaciones económicas desfavorables y de descenso de la demanda de mano de obra, la contratación

\footnotetext{
77 TASCÓN LÓPEZ, R. (2017), ob. cit., p. 137.

${ }^{78}$ MIÑARRO YANINI, E. (2014), ob. cit., p. 7/23.
} 
a tiempo parcial deja de ser una opción y se impone por la imposibilidad de encontrar un trabajo a tiempo completo, lo que explica el aumento del empleo a tiempo parcial en estos últimos años. Es verdad que, de acuerdo con el Informe del CES de 2016, el empleo a tiempo parcial involuntario ha comenzado a reducirse, pero esta característica sigue presente en dos tercios de los trabajos a tiempo parcial ${ }^{79}$, lo que, si se tiene además en cuenta la elevada tasa de temporalidad, afecta gravemente a la financiación de la Seguridad Social, por lo que deberían tomarse medidas para mejorar estas características del empleo ${ }^{80}$.

La imposibilidad de elegir también afecta al tiempo parcial como medida de conciliación, al impedir que "individuos que realmente quisieran optar a un puesto de trabajo que permitiese conciliar vida laboral y profesional no pueden hacerlo, al estar ocupado por

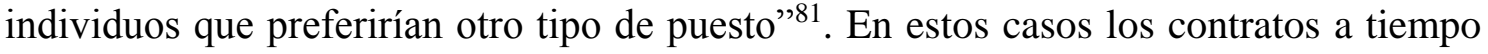
parcial se asemejan mucho a los supuestos de reducción de jornada por motivos familiares que recoge el ET, en los que se realiza una jornada inferior y se percibe una menor retribución, sin reconducirse el supuesto a un contrato ad $h o c^{82}$. Estas situaciones deberían ser consideradas tiempo parcial en atención a la Directiva 97/81/CE, pero, dado el criterio objetivo seguido por nuestro derecho, quedan al margen, al no concurrir el acuerdo de voluntades para constituir dicho contrato ${ }^{83}$.

Finalmente, la falta de elección y la precariedad resultante tienen también efectos en relación con la violencia en el trabajo. Efectivamente, en un concepto amplio de la violencia se puede entender que la imposición de condiciones precarias a los trabajadores es en sí misma una manera de violencia en el trabajo ${ }^{84}$, especialmente si, además, como en este caso, influye el factor de género. Es cierto, que reputados autores defienden que

79 CES (2017), Economía, Trabajo y Sociedad. Memoria sobre la situación socioeconómica y laboral. España 2016 [CD-ROM], Madrid: CES, p. 20. De acuerdo con la memoria de 2017 esta tendencia se mantiene y en el 2017 el número de trabajadores de ambos sexos que prestan servicios a tiempo parcial involuntariamente habría descendido del 61,9\% al 61,1\% —CES (2018), ob. cit., p. 351.

${ }^{80}$ COMISIÓN EUROPEA (2017), Informe sobre España 2017, con un examen exhaustivo relativo a la prevención y la corrección de los desequilibrios macroeconómicos. SWD(2017) 74 final [en línea]. Recuperado de https://ec.europa.eu/info/sites/info/files/2017-european-semester-country-report-spaines.pdf; y CES (2018), ob. cit., pp. 708 y 709.

${ }^{81}$ Cfr. BOTE Ál VAREZ CARRASCO, V.; CABEZAS ARES, A. (2012), ob. cit., p. 217.

82 TATAY PUCHADES, C. (2002), Seguridad Social y empleo atípico, en OISS, Empleo y Seguridad Social. La incidencia del desempleo, el empleo informal y las nuevas formas de empleo en la cobertura y la financiación de los Sistemas de Protección Social (pp. 83-248), Madrid: OISS, p. 95.

${ }^{83}$ Pese a ello la doctrina hace en ocasiones un tratamiento unitario de las mismas. Así, SIERRA HERNAIZ, E.; GOÑI SEIN, J. L. (2014), ob., cit., p. 2/15.

${ }^{84}$ Así lo señala Linares en relación a la situación impuesta de exclusión social y el concepto de violencia elaborado por Susan George que entiende que constituye una forma de la misma "todo aquello que impide que la gente satisfaga sus necesidades fundamentales: alimentación, vivienda, vestido, sí, pero también dignidad" - LINARES MÁRQUEZ DE PARDO, E. (), Alternativas. Cuadernos de trabajo social, (10), p. 257. También encajaría esta interpretación en otras definiciones que entienden la violencia en el trabajo como "cualquier acción, todo incidente o comportamiento que no pueda considerarse una actitud razonable y con el cual se ataca, perjudica, degrada o hiere a una persona dentro del marco de su trabajo o debido directamente al mismo" -KHALEF, A. (2004), ¿Es la violencia en el trabajo una fatalidad?, Educación Obrera, (133), p. 13. En este sentido, Jim Baker, Director de la Oficina de Actividades para los trabajadores de la OIT, apunta los múltiples factores que vinculan flexibilización y precariedad laboral con la violencia en el trabajo -BAKER, J. (2004), Editorial, en Educación Obrera, (133), p. VII y VIII. 
hay que desligar la violencia en el trabajo de otras figuras afines ${ }^{85}$, y que, entre las que menciona, como el ejercicio abusivo del poder empresarial o una gestión empresarial de notable severidad, podrían incluirse las situaciones de precariedad laboral, sobre todo si como en el caso que nos ocupa se encuentran legalizadas. Sin embargo, también es cierto que la presión laboral que sufren estos trabajadores en situación de precariedad puede considerarse un atentado a su integridad psíquica, por lo que puede entenderse que se produce una situación de violencia que lesiona el derecho fundamental a la integridad física y moral recogido en el art. $15 \mathrm{CE}$. En cualquier caso, lo que sí resulta más evidente es que la flexibilidad del mercado laboral, la precariedad laboral y social y la segregación por género - como la que provoca la involuntariedad predominante en la elección de la modalidad contractual-, aumentan las situaciones de violencia en el trabajo ${ }^{86}$, tanto los relativos a la salud y seguridad de los trabajadores - a mayor precariedad mayor índice de siniestralidad-, en especial en relación con los denominados riesgos psicosociales ${ }^{87}$, como las situaciones de acoso psicológico ${ }^{88}$, el acoso sexual ${ }^{89}$ y otras formas de acoso.

\subsection{Voluntariedad en la transformación del contrato}

El otro momento en el que la voluntariedad se erige como la piedra angular del contrato a tiempo parcial es en la transición entre un tipo de contrato y otro, impidiendo que el trabajador sea obligado a cambiar y posibilitando lo contrario, es decir, medidas que favorezcan el paso de una categoría a otra por decisión del trabajador.

A priori nuestro régimen jurídico se muestra contundente con esta idea. El art. 12.4.e ET determina que "la conversión de un trabajo a tiempo completo en un trabajo a tiempo parcial y viceversa tendrá siempre carácter voluntario para el trabajador (...)”. De esta manera, el tránsito de un contrato a otro requiere un pacto expreso y no se puede imponer unilateralmente, ni por el empresario, ni por los trabajadores. La legislación española impide este tránsito en cualquier sentido, mientras que en el ámbito comunitario la STJUE de 15 de octubre de 2015, C-221/2013 (Asunto Mascellani) ha entendido que no se opone a la Directiva 97/81/CE imponer al trabajador la transformación de un contrato a tiempo parcial en un contrato a tiempo completo ${ }^{90}$.

\footnotetext{
85 VALDÉS DAL-RÉ, F. (2013) Derecho Constitucional y violencia en el trabajo en España, Revista Internacional Comparada de Relaciones Laborales y Derecho del Empleo, 1(4), p. 12.

${ }^{86}$ DEMARET, L. (2004), La acción sindical frente a la violencia en el trabajo, Educación Obrera, (133), p. 45.

${ }^{87}$ RUANO ALBERTOS, S. (2017), ob. cit., pp. 44 y ss.; y TASCÓN LÓPEZ, R. (2017), ob. cit., pp. 143 y ss.

${ }^{88}$ RENAUT A. (2004), Acoso psicológico, nuevo mal vinculado a la organización en el trabajo, Educación Obrera, (133), p. 2.

${ }^{89}$ La diferencia de estatus laboral y las relaciones de poder entre hombres y mujeres, que provoca que sean mayoritariamente las trabajadoras quienes surgen este tipo de violencia fueron la base para entender estas conductas como una discriminación por razón sexo. Sobre el tema vid. ampliamente ALTËS TÁRREGA, J. A. (2000), El acoso sexual en el trabajo, Valencia: Tirant lo Blanch, pp. 26 y ss.

${ }^{90}$ Sobre el tema TAPIA HERMIDA, A., (2014) ¿Es posible proceder a la transformación de una relación laboral a tiempo parcial en una relación laboral a tiempo completo aun contra la voluntad del trabajador?, Revista de Trabajo y Seguridad Social. CEF, (381), pp. 177-181; BELTRÁN DE HEREDIA RUIZ, I. (2015), Directiva 97/81 sobre trabajo a tiempo parcial: conversión de tiempo parcial a tiempo completo, sí; ISSN: 2174-6419 Lex Social, vol. 9, núm. 2 (2019)
} 
Sin embargo, pese a la fuerza literal del precepto, las posibilidades que las partes del contrato de trabajo tienen para cambiar su estatus no es para nada homogéneo. Efectivamente, las aspiraciones de los trabajadores para acomodar la modalidad contractual a sus necesidades se han visto muy mermadas tras las últimas reformas legislativas.

Por un lado, el Real Decreto-Ley 16/2013, pese a resaltar las propiedades del contrato a tiempo parcial como instrumento de transición hacia el trabajo a tiempo completo, procedió a eliminar las preferencias que el art. 12 ET concedía a los trabajadores que hubieran cambiado voluntariamente de modalidad contractual para volver a su situación anterior. Sí se mantiene la obligación de informar a los trabajadores de la existencia de puestos de trabajo vacantes con el fin de que puedan formular sus solicitudes de conversión voluntaria que se tramitaran conforme a los procedimientos establecidos en el convenio colectivo y debe recordarse aquí que este instrumento negocial ha sufrido un importante revés en las últimas reformas legislativas, minorando su poder como instrumento modulador de las relaciones laborales. Además, la existencia de solicitudes no conlleva una correlativa obligación empresarial de atenderlas, tan sólo se exige que se tomen en consideración en la medida de lo posible y que se motive su denegación (art. 12.4e ET). El empresario puede así mantener los costes del contrato a tiempo parcial en el tiempo a costa de limitar los derechos de los trabajadores.

Por otro lado, también se ha eliminado la prerrogativa que tenía la negociación colectiva para favorecer la conversión de un contrato a tiempo completo en parcial por motivos familiares o formativos. Como puede observarse, estos elementos limitan mucho la voluntariedad que preside el trabajo a tiempo parcial y aumentan el poder de decisión del empresario que ya no posee condicionantes que lo limiten ${ }^{91}$.

Es decir, aunque en apariencia se mantiene un régimen jurídico tuitivo para el trabajador, lo cierto es que se ha minimizado considerablemente su impacto.

En cambio, el tratamiento que se da a la prohibición empresarial para imponer unilateralmente un cambio de contrato no es tan taxativo como pudiera parecer de la lectura de la normativa. Efectivamente, en sintonía con la afirmación inicial que contiene el art. 12.4.e. ET, también se impide que la novación contractual se ampare en una "modificación sustancial de condiciones de trabajo al amparo de lo dispuesto en el artículo 41.1.a)", redundando en la idea de que el empresario no puede en ningún caso imponer esta novación contractual. Por último, en esta misma línea, se establece que el "trabajador no podrá ser despedido ni sufrir ningún otro tipo de sanción o efecto perjudicial por el hecho de rechazar esta conversión, sin perjuicio de las medidas que,

conversión de tiempo completo a parcial, no (comentario a la SSTJUE 15.10.2014, C221/2013, Revista de Información Laboral, (2), pp. 133-139; y NUÑEZ-CORTÉS CONTRERAS, P. (2016), Puntos críticos en relación al principio de voluntariedad en el contrato a tiempo parcial, Revista General de Derecho del Trabajo y de la Seguridad Social, (42), pp. 234 y ss.

${ }^{91}$ MIÑARRO YANINI, M. (2014), ob. cit., p. 6/23.

ISSN: 2174-6419

Lex Social, vol. 9, núm. 2 (2019) 
de conformidad con lo dispuesto en los artículos 51 y 52.c), puedan adoptarse por causas económicas, técnicas, organizativas o de producción".

Debe tenerse presente que la conversión de un contrato a tiempo completo en un contrato a tiempo parcial no es únicamente una modificación de la jornada de trabajo, sino que tiene importantes efectos en el régimen jurídico aplicable a la relación contractual, lo que justifica que se derive a la existencia de un pacto novatorio. En la actualidad, el artículo $12 \mathrm{ET}$, al igual que las normas internacionales y comunitarias de las que trae causa, en especial la Directiva 97/81/CE, relativa al AMTTP, no ofrece duda alguna de que la conversión requiere en todo caso la concurrencia de la voluntad del trabajador afectado, impidiendo que el empresario adopte esta decisión en el marco del Estatuto de los Trabajadores $^{92}$.

Pese a ello, el principio de voluntariedad se ve ha afectado por decisiones empresariales en dos supuestos: 1) porque la ambigüedad en el precepto en relación con la garantía de indemnidad ha dado lugar a situaciones ciertamente permisivas cuando la novación contractual se une a un despido por causas empresariales; y, 2) porque, la legislación y la jurisprudencia permiten fórmulas que permiten reducir la jornada sin que impliquen una novación.

\subsubsection{La conversión como fórmula para evitar un despido colectivo}

Muchas veces, el paso de una actividad a tiempo completo a otra a tiempo parcial puede ser un factor que impida o minimice el impacto de un despido colectivo. Efectivamente, frente a la decisión empresarial de extinguir el contrato de un número concreto de trabajadores de una determinada sección o categoría profesional, cabe plantear como opción la conversión de los contratos a tiempo completo en contratos a tiempo parcial, por lo que debemos preguntarnos si con ello se vulnera la prohibición del art. $12 \mathrm{ET}^{93}$.

Antes de la supresión de la autorización administrativa en los expedientes de regulación de empleo se produjo una corriente judicial que admitía esta posibilidad, sustituyendo la voluntad del trabajador por la autorización de la Autoridad Laboral. Así, la STSJ CastillaLa Mancha de 4 mayo 2006, Rec. 720/2006, señalaba que si bien "no es posible la conversión del contrato si no media el consentimiento del trabajador, aunque, como excepción, se permite la utilización de las medidas previstas en los antecitados artículos 51 y 52 c) ET, con lo que cabría la conversión unilateral del contrato a través de un expediente".

\footnotetext{
92 El precepto, en su actual redacción, dada por el RD-Ley 15/1998, de 27 de noviembre, de medidas urgentes para la mejora del mercado de trabajo en relación con el trabajo a tiempo parcial y el fomento de su estabilidad, disipa las dudas doctrinales y judiciales planteadas al respecto con anterioridad. Sobre estas posturas vid LOUSADA AROCHENA, J. F. (2001), El principio de voluntariedad en el nuevo régimen legal del trabajo a tiempo parcial, Aranzadi Social, T. V, p. 607.

93 GARCÍA TESTAL, E.; ALTÉS TÁRREGA, J. A. (2010). Contrato a tiempo parcial, reducción de jornada y crisis económica, en CAMPS RUIZ, L. M.; RAMÍREZ MARTÍNEZ, J. M.; SALA FRANCO, T. (Coords.), Crisis, Reforma y Futuro del Derecho del Trabajo (pp. 133-148), Valencia: Tirant lo Blanch, pp. 137 y ss.
} 
Como he expresado en otros estudios, una actuación imperativa de este tipo no es posible, por cuanto se aparta de la requerida voluntariedad en la novación contractual, de manera que el hecho de que se ampare en un expediente de regulación de empleo, no conlleva una obligación para los trabajadores afectados. Sin embargo, la conversión de tiempo completo en tiempo parcial sí puede formar parte del contenido del período de consultas y del posible acuerdo, por lo que cabría que los representantes de los trabajadores aceptaran recomendar a los trabajadores la necesidad de proceder a la conversión de los contratos, si bien estos serán libres para aceptar la propuesta mediante el correspondiente pacto novatorio ${ }^{94}$. De hecho, un acuerdo de este tipo no parece que se aparte del contenido de la negociación de un expediente de regulación de empleo que, de acuerdo con el art. 51.2 ET, “deberá versar, como mínimo, sobre las posibilidades de evitar o reducir los despidos colectivos y de atenuar sus consecuencias mediante el recurso a medidas sociales de acompañamiento, tales como medidas de recolocación o acciones de formación o reciclaje profesional para la mejora de la empleabilidad".

Ahora bien, en este contexto es imprescindible dar mayores garantías a la voluntariedad, para evitar que el trabajador ceda intimidado ante la alternativa de perder el empleo, poniendo en tela de juicio la supuesta libertad en la elección ${ }^{95}$. De hecho, las garantías que introduce el actual del art. 12 ET resultan insuficientes cuando lo que se plantea al trabajador es la alternativa entre la transformación del contrato o su extinción, sobre todo en situaciones de crisis como la que todavía persiste a nivel de empleo ${ }^{96}$. Pese a ello, la doctrina judicial, cuando se ha ocupado del tema, no ha entrado a valorar la concurrencia de intimidación en el consentimiento prestado por el trabajador, entendiendo, por el contrario, que plantear la opción entre conversión o extinción "no posee mayor trascendencia que la de ser uno de los elementos tomados en cuenta por el trabajador a la hora de aceptar o rechazar la conversión producida",97.

\subsubsection{La conversión y el despido objetivo individual.}

Aún resulta más problemática la oferta empresarial de conversión del contrato de trabajo como fórmula de evitar un despido objetivo individual o plural a través del 52.c ET, ya que en estos supuestos no se precisa la intervención de los representantes de los trabajadores.

\footnotetext{
${ }^{94}$ GARCÍA TESTAL, E.; ALTÉS TÁRREGA, J. A. (2010), ob. cit., pp. 138 y ss. En similar sentido, SALA FRANCO, T. (2000), Los principios de ordenación del contrato de trabajo a tiempo parcial, en CASAS BAAMONDE, M. E.; VALDÉS DAL-RÉ, F. (Coords.) Los contratos de trabajo a tiempo parcial, Valladolid.

95 FERRADANS CARAMES, C. (2006), El contrato de trabajo a tiempo parcial. Difícil equilibrio entre flexibilidad y seguridad, Cizur Menor (Navarra): Thomson Reuters-Aranzadi, p. 191; GARCÍA TESTAL, E.; ALTÉS TÁRREGA, J. A. (2010), ob. cit., p. 140.

96 Aunque desde 2013 se ha recuperado progresivamente el empleo, hasta llegar a un 15,9\% de tasa de desempleo en abril de 2018, se está todavía lejos del nivel de 2007, en que se situaba en el 8,57\%, además de que la mayor parte del empleo que se ha creado tiene una alta dosis de precariedad.

${ }^{97}$ SSTSJ Castilla y León-Valladolid de 9 marzo de 2004, Rec. 2843/2004. Admiten igualmente estos pactos la STSJ Castilla y León-Valladolid, de 30 marzo 2004, Rec. 51/2004; la STSJ Castilla y León-Valladolid, de 15 julio 2004, Rec. 52/2004; y la STSJ Islas Canarias-Las Palmas, de 30 de junio de 2016, Rec. 141/2016. ISSN: 2174-6419 Lex Social, vol. 9, núm. 2 (2019)
} 
Sin embargo, la doctrina judicial ya venía admitiendo que la novación del contrato se oferte expresamente como la alternativa a ser despedido por causas económicas ${ }^{98}$ y esta interpretación ha ido extendiéndose a otros órganos judiciales con capacidad de sentar doctrina como el Tribunal Supremo y el propio Tribunal Constitucional.

En este sentido, la STSJ Castilla-La Mancha de 8 de noviembre de 2012, Rec. 1312/2012, convalidó el despido de una trabajadora justificado por la existencia de graves causas económicas que previamente había rechazado hasta dos ofertas de reducción de jornada y salario. La trabajadora demandó amparo ante el Tribunal Constitucional que fue desestimado en la STC 183/2015, de 10 de diciembre, al entender que no resulta vulnerado el art. 24.1 CE, en relación con la garantía de indemnidad que impide al empresario represaliar al trabajador que ha ejercido la tutela de sus derechos, si, como en el caso que se enjuicia, tras la impugnación de una drástica oferta de reducción de jornada por parte de la trabajadora y la posterior conciliación judicial, se hace otra oferta menos gravosa, lo que impide constatar la voluntad represaliadora de la empresa en la decisión extintiva que, por otro lado, se ajusta plenamente al régimen causal exigido.

De forma similar, la STSJ Extremadura de 10 de mayo de 2016, Rec. 163/2016, validó el despido, vía art. 52.c ET, de un trabajador que había no había aceptado una conversión de su contrato al entender que existían realmente causas económicas. Y la STS de 30 de mayo de 2018, Rec. 2329/2016, ha confirmado esta sentencia, declarando procedente el despido realizado por la vía del 52.c) ET ante la negativa del trabajador a aceptar una reducción de la jornada de trabajo, sin que sea necesario acudir a la vía del art. 41 ET.

Podría argumentarse que la solución podría haber variado si el conflicto se hubiera articulado en torno al derecho de indemnidad, aunque la rigurosa interpretación del derecho de indemnidad que ha establecido el Tribunal Constitucional en estos casos no ayuda mucho, o en la ausencia de causas objetivas.

En mi opinión la tesis mantenida por el Tribunal Supremo puede ser ciertamente peligrosa, en cuanto que en adelante se va a condicionar enormemente la voluntad del trabajador ante este tipo de ofertas. Coincidimos con la doctrina en que, ante la existencia de otros mecanismos, como el art. 47.2 ET al que más adelante nos referimos, que permiten una reducción temporal de la jornada por estas causas, la reducción de la jornada o el cambio contractual han de ser ajenos a cualquier tipo de condicionante, por lo que la decisión del Tribunal Constitucional tendría que haberse movido en esta línea ${ }^{99}$.

\footnotetext{
${ }^{98}$ Vgr. STSJ Madrid 9 abril 2007, Rec. 238/2007, S. 238/2007. En la sentencia se valida la actuación de la empresa que "ofreció a la trabajadora, mediante carta de 2-3-05, la posibilidad de reducir de mutuo acuerdo su jornada, (...), advirtiendo que, de no responder en el plazo de dos días, se llevaría a cabo el despido objetivo. La actora no efectuó contestación alguna y la empresa le comunicó el despido por causas organizativas y productivas...".

${ }^{99}$ En el mismo sentido, CABEZA PEREIRO, J.; LOUSADA AROCHENA, F. (2018), ob. cit., p. 429. De hecho, la STC 183/2015, de 10 de diciembre, contiene un voto particular al que se adhieren cuatro magistrados, que sí entiende que, pese a la existencia de una causa legal, la empresa no ha logrado acreditar que su actuación esta desvinculada del ejercicio de acciones judiciales de la recurrente en amparo. 
Por ello, en estos casos debería prohibirse también esta posibilidad o bien, saliendo del paso, incrementarse las garantías otorgadas normativamente a los trabajadores afectados por la conversión. Y así, a modo de ejemplo, además de la presencia de un representante de los trabajadores, como fuente de información de la concurrencia de la causa, debería priorizarse el establecimiento de la temporalidad de la transformación (vinculada por tanto de manera estricta a la superación de la situación negativa en la empresa), y, en consecuencia, el retorno a la jornada previamente realizada ${ }^{100}$.

\subsubsection{Reducción de jornada por causas empresariales y tiempo parcial.}

Al margen de la conversión del contrato stricto sensu, también debemos prestar atención a otra fórmula que la empresa puede explorar para imponer un tiempo de trabajo menor. Las posibles vías que la ley proporciona para lograr este resultado serían la modificación sustancial del contrato que regula el art. 41 ET y la reducción de jornada a la que se refiere el art. 47.2 ET por causas económicas, técnicas y de producción. Es decir, se trata de determinar si es posible establecer una reducción de jornada que no suponga una novación contractual, en cuyo caso, al igual que ocurría anteriormente con los supuestos de guarda legal y otros asimilados a los que se refieren los arts. 37.4 y ss. ET, nos encontraríamos ante otra situación derivada del entendimiento del tiempo parcial de forma objetiva y no subjetiva.

Se trata de una cuestión conflictiva que parece situarse al margen de la amplia definición del contrato a tiempo parcial, en la que el legislador, pese al criterio objetivo usado, parece querer reconducir a su régimen jurídico cualquier prestación de servicios que se efectúe con una jornada (cualquiera) inferior a la del trabajador comparable a tiempo completo ${ }^{101}$.

\subsubsection{La reducción de jornada como modificación sustancial del contrato.}

Para dirimir si es posible la imposición de una jornada inferior por vía del art. 41 ET, hay que clarificar si dicho precepto ampara esta posibilidad de reducción de la jornada o si solamente se permite modificar las relativas a la distribución (regular o irregular) de la jornada.

Pues bien, en principio, admite esta posibilidad, pues, al listar las posibles condiciones de trabajo modificables, se refiere de forma diferenciada, no solo a la jornada y al horario, sino también a la distribución del tiempo de trabajo, por lo que la alusión a la jornada se conecta necesariamente con los incrementos y reducciones del número de horas trabajadas $^{102}$.

\footnotetext{
${ }^{100}$ GARCÍA TESTAL, E.; ALTÉS TÁRREGA, J. A. (2010), ob. cit., p. 141.

${ }^{101}$ GARCÍA TESTAL, E.; ALTÉS TÁRREGA, J. A. (2010), ob. cit. pp. 141 y 142.

102 GARCÍA TESTAL, E.; ALTÉS TÁRREGA, J. A. (2010), ob. cit. pp. 142 y 143. Con anterioridad a la reforma del art. 41 algunos autores negaban esta posibilidad - MIRANZO DÍEZ, J. J. (2009), Reducción de jornada en el contrato a tiempo parcial, modificación sustancial de las condiciones de trabajo, y vías procesales para recurrir, Aranzadi Social (10), recuperado de BD Aranzadi Instituciones, Ref. BIB 2009/866, p. 5/6-, mientras que otros mantenían la virtualidad del art. 41 para proceder a una reducción ISSN: $2174-6419$ Lex Social, vol. 9, núm. 2 (2019)
} 
Ahora bien, no basta con que el supuesto se encuadre en el elenco de posibilidades del art. 41, pues, como ya se ha dicho, cabe argumentar que con este proceder se habilita una vía de escape para el empresario que le permitiría evitar la aplicación del art. 12.4.e ET y la normativa comunitaria de la que trae causa. En este sentido, la STC 213/2005, de 21 de julio, determinaba, en relación con la redacción del artículo 12 fijada por el Real Decreto-ley 39/1998, de 27 de noviembre, que no era posible utilizar el art. 41 ET para reducir la jornada de trabajo en más de un tercio, "dado que una tal reducción de jornada implicaría la conversión del contrato a tiempo completo en un contrato «a tiempo parcial» y tal conversión «tendrá siempre carácter voluntario para el trabajador, y no se podrá imponer de forma unilateral o como consecuencia de una modificación sustancial de condiciones de trabajo» [art. 12.4 e) LET], de manera que la exclusión legal de la protección por desempleo de las situaciones derivadas de dichos supuestos habrá de ser valorada, a partir de dicho momento, teniendo en cuenta el dato legal sobrevenido del carácter necesariamente voluntario para el trabajador de tales modificaciones. Más aún tras la última reforma de la definición legal del contrato a tiempo parcial operada por la Ley 12/2001, de 9 de julio, a partir de la cual cualquier reducción de jornada por debajo de la ordinaria implica la conversión del contrato a tiempo completo en un contrato a tiempo parcial y, por lo tanto, conlleva necesariamente la exigencia de voluntariedad en la reducción y la exclusión de la aplicación del art. 41 LET'.

Sin embargo, la jurisprudencia del Supremo esquivó esta doctrina en dos sentencias muy criticadas ${ }^{103}$. En la primera de ellas, la STS de 14 de mayo de 2007, Rec. 85/2006, se negó que la imposición de una jornada reducida por la vía del art. 41 ET pudiera considerarse como un supuesto de despido. Los trabajadores demandantes esgrimían que la reducción de la jornada extinguía el vínculo laboral original y constituía uno nuevo a tiempo parcial. La Sala estima que no existe voluntad extintiva, sino de modificación sustancial del contrato y que el contrato a tiempo parcial no cabe identificarlo "como un simple supuesto de reducción de jornada [contrato de trabajo a tiempo completo con jornada reducida] o de utilización reducida del tiempo de trabajo [ «jornada parcial»]”. Además, recuerda que para su nacimiento se requiere, junto con la existencia de una jornada reducida, la voluntad de las partes para sujetarse a dicha modalidad contractual. De esta manera, la imposición ex art. 41 de una jornada reducida, en atención al art. 12.4.e ET, no puede considerarse una novación extintiva que da paso a un contrato parcial, "sino la mera reducción de la jornada en contrato a tiempo completo que persiste como tal categoría jurídica, pues la específica modalidad de que tratamos [contrato a tiempo parcial] únicamente puede ser fruto de una conversión contractual que se instrumente por medio de una novación extintiva, que en todo caso es requirente de la voluntad concorde del

de jornada sin transformar el contrato - VICEDO CAÑADA, L. (2009), De contrato a tiempo completo a contrato a tiempo parcial. Una solución para las PYMES en tiempos de crisis, Madrid, pp. 140 y ss.

${ }^{103}$ Sobre la controversia judicial en esta materia vid. NUÑEZ-CORTÉS CONTRERAS, P. (2016), ob. cit., pp. 240 y ss. 
trabajador" 104 . Aun así, la sentencia consideró irregular la actuación empresarial, si bien no procedió a valorarla por no ser objeto del recurso.

Lo que viene a decir el Tribunal Supremo es que, al no existir acuerdo de voluntades, la modalidad contractual se mantiene, por lo que se trataría de trabajadores a tiempo completo con reducción de jornada. El argumento, "jurídicamente impecable para unos"105 y "sorprendente" y "difícilmente comprensible" para otros ${ }^{106}$ debe exigir, como señala la doctrina, que los trabajadores sean tratados como trabajadores a tiempo completo a todos los efectos, so pena de convertirse en "una muestra más de la precariedad en el empleo consecuencia de la crisis y de las decisiones políticas para abordarlas" $" 107$.

Sin embargo, en mi opinión, la imposición de una jornada reducida con carácter permanente sólo puede entenderse como un supuesto de conversión del contrato, como un tránsito desde el tiempo completo al tiempo parcial y, por tanto, una conducta incluida en la prohibición del art. 12.4.e ET, que, de esta manera, debería ser aún más explícito con el fin de evitar este tipo de interpretaciones ${ }^{108}$. Sí podría utilizarse en cambio para aumentar la jornada dentro de los límites legales, tanto en los contratos a tiempo completo como a tiempo parcial, o bien para reducir la jornada de un contrato a tiempo parcial ${ }^{109}$.

Parece entonces, que la reducción de la jornada de un contrato a tiempo completo, con el fin de salvar esta contradicción, exige, además de concurrir una de las causas exigibles, que la modificación posea un límite temporal ${ }^{110}$. Este fue precisamente uno de los argumentos utilizados por la STS de 7 de octubre de 2011, Rec. 144/2011, para validar la reducción de una jornada por la vía del art. 41. La Sala insiste en la idea expresada por la STS de 14 de mayo de 2007 y no considera una novación extintiva la imposición de una

\footnotetext{
${ }^{104}$ En similar sentido la STS de 18 septiembre 2008, Rec. 1875/2007.

${ }^{105}$ ESPÍN SÁEZ, M. (2015), ob. cit. p. 150. También parece compartir el argumento del Tribunal Supremo CALLADU DALMAU, P. (2018), El principio de voluntariedad como presupuesto sustantivo del trabajo a tiempo parcial, Lan Harremanak, (39), p. 200.

106 BELTRÁN DE HEREDIA RUIZ, I. (2013), «Principio de voluntariedad» ex art. 12.4.e) ET: Un obstáculo (infranqueable) para la reducción de jornada ex arts. 41 y 47 ET, Actualidad Laboral, (6). Recuperado de BD La Ley Digital, Ref. LA LEY 2899/2013, p. 1/10.

${ }^{107}$ ESPÍN SÁEZ, M. (2015), ob. cit. p. 150; y ESPÍN SÁEZ, M. (2016), El contrato a tiempo parcial ¿la conciliación en los tiempos de precariedad? [en línea], Revista de Información Laboral, (12). Recuperado de BD Aranzadi Instituciones, Ref. BIB 2017\10563, p. 10/18.

${ }^{108}$ GARCÍA TESTAL, E.; ALTÉS TÁRREGA, J. A. (2010), ob. cit., pp. 142 y 143; BELTRÁN DE HEREDIA RUIZ, I. (2013), «Principio de voluntariedad» ex art. 12.4.e) ET: Un obstáculo (infranqueable) para la reducción de jornada ex arts. 41 y 47 ET, Actualidad Laboral, (6). Recuperado de BD La Ley Digital, Ref. LA LEY 2899/2013, p. 2/10; MURCIA CLAVERÍA, A. (2017), La reducción de jornada como modificación sustancial de condición de trabajo, el principio de voluntariedad y la garantía de indemnidad, Nueva Revista Española de Derecho del Trabajo, (203), p. 276.; CABEZA PEREIRO, J.; LOUSADA AROCHENA, F. (2018), ob. cit., p. 425.

${ }^{109}$ CRUZ VILLALÓN, J. (2008), Modificación del tiempo de trabajo, en APARICIO TOVAR, J.; LÓPEZ GANDÍA, J. (Coords.), Tiempo de trabajo, Albacete: Bomarzo, p. 249; BELTRÁN DE HEREDIA RUIZ, I. (2013), ob. cit., p. 2/10; MURCIA CLAVERÍA, A. (2017), ob. cit., p. 276.

110 BLASCO PELLICER, A. (2007), Los procedimientos de regulación de empleo, Valencia: Tirant lo Blanch, p. 97; GARCÍA TESTAL, E.; ALTÉS TÁRREGA, J. A. (2010), ob. cit., p. 143. Sin embargo, para otro sector de la doctrina, la dicción del art. 12 también impide la reducción temporal o provisional de la jornada -BELTRAN DE HEREDIA RUIZ, I. (2013), ob. cit., p. 2/10.
} 
jornada reducida por esta vía al no concurrir la voluntad del trabajador. En consecuencia, defiende que "la reducción de la jornada de las cuatro trabajadoras demandantes en un 30,5\% de la jornada decidida unilateralmente por la empresa ante la disminución no discutida de la actividad empresarial, no supuso una vulneración de lo previsto en el artículo 12.4 e) ET, desde el momento que esa decisión empresarial y la ausencia de conformidad de las trabajadoras no determinaban la transformación del contrato a tiempo completo en otro a tiempo parcial, tal y como se afirma en la sentencia recurrida, máxime cuando la media adoptada tenía el carácter de temporal, aunque ciertamente no se identificase el tiempo durante el que habría de producir efectos".

La doctrina ha sido igualmente crítica con esta sentencia y recuerda que la STJUE de 15 de octubre de 2014, C-221/13 (Asunto Mascellani), que avaló un supuesto de conversión unilateral de un contrato a tiempo parcial en otro a tiempo completo, señala que la situación contraria no es comparable, "pues la reducción del tiempo de trabajo no tiene las mismas consecuencias que su incremento, en particular, en el plano de la remuneración del trabajador, que constituye la contrapartida del trabajo" ${ }^{111}$.

En cualquier caso, aunque se admitiese esta argumentación, negada tajantemente por parte de la doctrina ${ }^{112}$, lo cierto es que la actual configuración normativa planteada por el Estatuto en relación con la reducción de jornada como medida para paliar una situación de ineficiencia económica en el art. 46.2 puede impedir de facto la aplicación del art. 41 ET.

\subsubsection{La reducción temporal de jornada ex art. 47 ET.}

En su actual configuración, el art. 47.2 ET, posibilita expresamente una reducción de la jornada basada en causas empresariales siguiendo el mismo procedimiento que para la suspensión del contrato de trabajo por causas económicas, técnicas, organizativas o de producción, entre un 10 y un $70 \%$ de la jornada computada sobre la base de una jornada diaria, semanal, mensual o anual ${ }^{113}$. Por tanto, el empresario podrá aplicar la reducción de jornada, pese a que no exista acuerdo con la representación de los trabajadores,

\footnotetext{
${ }^{111}$ CABEZA PEREIRO, J.; LOUSADA AROCHENA, F. (2018), ob. cit., p. 425.

112 BELTRÁN DE HEREDIA RUIZ, I. (2013), ob. cit., p. 6/10.

${ }^{113}$ Esta posibilidad se introdujo como consecuencia de la Ley 35/2010, de 17 de septiembre, de medidas urgentes para la reforma del mercado de trabajo; y el RD-Ley 3/2012, de 10 de febrero, de medidas urgentes para la reforma del mercado laboral. Ya con anterioridad a la reforma la aplicación de estas reducciones se había desplazado al artículo 47 ET, debido a la exigencia del requisito de autorización administrativa que contemplaba el art. 203.3 LGSS para acceder a la percepción de prestaciones por desempleo —GOERLICH PESET, J. M. (2007), El concepto de modificación sustancial de las condiciones de trabajo en la jurisprudencia del Tribunal Supremo, Aranzadi Social (5), recuperado de BD Aranzadi Instituciones, Ref. BIB 2007/1694, p. 9/13; GARCÍA TESTAL, E.; ALTÉS TÁRREGA, J. A. (2010), ob. cit., p. 143. Se entendía la reducción del tiempo de trabajo como un supuesto de suspensión de contrato, ya que el cese en la prestación de servicios podrá suceder durante algún período del año, del mes, de la semana o incluso mediante una reducción de las horas de trabajo diario (reducción de jornada) -BLASCO PELLICER, A. (2009), o. cit., pp. 461 y 462; NORES TORRES, L. E. (2000), El período de consultas en la reorganización productiva empresarial, Madrid: CES, p. 97. Se ha mostrado especialmente crítico con esta construcción BELTRAN DE HEREDIA RUIZ, I. (2013), ob. cit., p. 5/10.
} 
ejerciendo el control de legalidad la jurisdicción social previa impugnación de la misma en vía colectiva o individual.

El elemento temporal que se deduce de la equiparación con los supuestos de contratación temporal permite alejar este supuesto del de la novación contractual. Además, el hecho de que existan unas causas habilitantes permite objetivizar la decisión y apartarla de la concurrencia de voluntades necesaria para formalizar un contrato a tiempo parcial. Este mismo régimen causal concede cierta seguridad, en tanto que será fiscalizada por los representantes de los trabajadores y, en su caso, por el juez laboral. De hecho, esta forma de reducción de jornada sí viene aceptada en la normativa internacional como un supuesto que no configura el tiempo parcial. En este sentido, el art. 1.d del Convenio 175 OIT determina que "no se considerará trabajadores a tiempo parcial a los trabajadores a tiempo completo que se encuentres en situación de desempleo parcial, es decir, aquellos que estén afectados por una reducción colectiva y temporal de la duración normal de su trabajo por motivos, económicos, tecnológicos o estructurales".

Pues bien, en relación con la afirmación realizada al final del anterior apartado, hay que señalar que, al configurarse el expediente de regulación de empleo por reducción de jornada con carácter cuantitativamente omnicomprensivo (art. 47.1, párrafo 4 ET), absorbe todas las situaciones a las que se refiere el artículo $41 \mathrm{ET}$, lo que impide utilizar el procedimiento en él contenido para reducir la jornada.

El único espacio de aplicación potencialmente del art. 41 ET ha de referirse a los supuestos de ampliación de la jornada, y a los de reducción de jornada (tanto de contratos a tiempo completo como de contratos de tiempo parcial) que no quedan comprendidos en el ámbito del art. 47.2 ET, aunque ni siquiera en estos supuestos parece que pueda tener efectividad.

En primer lugar, porque, si la reducción de la jornada, sin importar el porcentaje, tiene carácter definitivo se produciría una novación contractual que, como se ha reiterado está taxativamente vedada, salvo que se nazca del acuerdo de voluntades.

En segundo lugar, porque las reducciones de jornada temporales superiores a un $70 \%$ debe entenderse que están prohibidas, pues, en otro caso, se llegaría al absurdo de admitir que si se supera dicho límite el procedimiento sería más sencillo —modificación sustancial individual o colectiva del art. $41 \mathrm{ET}$ - que si no se alcanza —expediente de regulación de empleo del artículo 47 ET-, amén de que el trabajador no gozaría de la protección por desempleo.

De esta manera, la empresa sólo podría imponer una reducción de jornada por la vía de art. 41 ET cuando sea temporal e inferior al 10\% de la jornada ordinaria de un trabajador comparable, siempre que la misma tenga origen en pacto individual o en un pacto colectivo o una decisión empresarial de carácter colectivo, pues si la jornada cuya reducción se pretende está fijada en convenio colectivo estatutario tampoco será posible 
imponerla unilateralmente, ya que en este caso se impone la existencia de un pacto modificativo con los representantes de los trabajadores (art. 82.3 ET).

De todas formas, si bien es cierto que la reducción de jornada, en la medida en que supone también una reducción del salario, avala la atribución del carácter sustancial a estas modificaciones de jornada, con independencia del quantum de la reducción, bien mirado una reducción inferior al 10\% implica como mucho minorar la jornada en 182 horas anuales, esto es, en torno a 4 horas a la semana, lo que, unido al carácter temporal de la medida, bien podría llevarnos a entender que no estamos ante un supuesto de modificación sustancial, sino ante una prerrogativa empresarial comprendida en su ius variandi $^{114}$.

\section{Conclusión: El necesario cambio de rumbo legislativo}

Al comenzar este trabajo se ha hecho referencia a la ambivalencia del contrato de trabajo a tiempo parcial como un mecanismo capaz de armonizar los distintos intereses en juego. Sin embargo, en su desarrollo se ha podido constatar que la profunda integración de la flexibilización empresarial y su uso como mecanismo anticrisis han hecho que se aleje "de aquella función equilibradora de intereses con la que fue diseñado" $"$.

No es de extrañar, por tanto, que esta institución haya cosechado abundantes críticas por parte de la doctrina española. Quizás la más contundente es la que directamente entiende que esta regulación infringe directamente la normativa internacional que lo ampara, pues se ha convertido en un elemento de precarización de los elementos más vulnerables de la población y no favorece la conciliación ${ }^{116}$; y, añado yo, potencia la discriminación por razón de género, nos aleja de los estándares de un trabajo decente y aumenta la posibilidad de sufrir violencia en el trabajo. La continua flexibilización del contrato a tiempo parcial lo sitúan, más que como una modalidad contractual, como un formula flexible de organizar el tiempo de trabajo, lo que resulta muy evidente en relación con las horas complementarias, cuyo régimen jurídico, se ha dicho, raya lo delirante ${ }^{117}$. Para evitar esta situación debería apostarse por legislar reequilibrando el juego de intereses, revisando aquellos elementos que precarizan el trabajo parcial, impiden la elección voluntaria y que, además, crean impacto de género.

Así, en relación con las horas complementarias, debería actuarse remodelándolas o incluso suprimiéndolas, aun a costa de rescatar las horas extraordinarias con carácter exclusivamente voluntario ${ }^{118}$. Entretanto ha de aumentarse el control para evitar fraudes, ya que la difuminada línea que separa el tiempo de trabajo parcial y completo posibilita

${ }^{114}$ Estas mismas consideraciones en ALTÉS TÁRREGA, J. A.; GARCÍA TESTAL, E. (2013), Crisis económica y tiempo de trabajo: reducción de jornada y trabajo a tiempo parcial [CD-Rom], en Jornadas hispano-italianas sobre reformas legislativas del derecho laboral en tiempos de crisis, Valencia: Low cost books, pp. 233 y ss.

115 ESPÍN SÁEZ, M. (2015), El contrato a tiempo parcial: de la oportunidad de generar empleo a la precariedad en el empleo, Revista Jurídica de la Universidad Autónoma de Madrid, 1(31), pp. 142.

${ }^{116}$ ESPÍN SÁEZ, M. (2016), ob. cit., p. 18/18.

117 TASCÓN LÓPEZ, R. (2017), ob. cit., p. 139.

${ }^{118}$ CABEZA PEREIRO, J.; LOUSADA AROCHENA, F. (2018), ob. cit., p. 428.

ISSN: 2174-6419

Lex Social, vol. 9, núm. 2 (2019) 
un mal uso de la institución y la realización de horas irregularmente ${ }^{119}$. En este control tendrá un papel clave el registro de la jornada diaria que el nuevo art. $34.9 \mathrm{ET}^{120}$ impone a las empresas.

Para reforzar la voluntariedad en la elección de la modalidad contractual deberían instaurarse fórmulas que permitieran el tránsito en uno y otro sentido entre el tiempo parcial y el tiempo completo. La actual regulación convierte prácticamente el trabajo a tiempo parcial en un punto de llegada y no en el primer paso hacia un contrato a tiempo completo. El debilitamiento del papel de la negociación colectiva transforma en papel mojado algunas de las previsiones que la ley mantiene en este sentido. Para evitarlo, se deberían Incorporar ciertos derechos absolutos próximos a los que se reconocen en los casos de reducción de jornada por motivos familiares que permitan el tránsito de una modalidad a otra. De hecho, sería deseable que ambas situaciones (reducción de jornada y contrato a tiempo parcial) se equipararan y se integraran en un mismo régimen jurídico atendiendo a un criterio subjetivo de tiempo parcial, algo por lo que apostaba la caducada por el cierre de la última legislatura Proposición de Ley de tiempo de trabajo corresponsable presentada por grupo parlamentario Unidos Podemos, En comú, Podem, En Marea, en noviembre de 2018. Sin embargo, hoy por hoy resulta mejor para el trabajador con reducción de jornada no ser considerado trabajador a tiempo parcial, por lo que dicha equiparación debería producirse, como señala la doctrina, en un contexto más equilibrado en el que el contrato parcial recupere parte del espíritu tuitivo para el trabajador que se ha ido perdiendo con las sucesivas reformas sobre la base de introducir cada vez mayor flexibilidad y por tanto menor control de su tiempo ${ }^{121}$.

Otro aspecto en el que necesariamente debería incidir el legislador para evitar la inseguridad jurídica actual es en la delimitación de los supuestos de reducción de la jornada por causas objetivas. Esta institución jurídica introduce precarización en los contratos y reduce cuantiosamente los salarios de los trabajadores, por ello parece razonable que se establezcan límites más precisos, amplíen las garantías y se eviten la inseguridad jurídica actual.

A la vista de lo planteado parece necesaria la intervención del legislador tanto para aclarar cuáles son las vías para reducir la jornada en atención a los procedimientos existentes, si bien, mientras esto no ocurra lo aconsejable es seguir la vía del art. 47 ET.

En materia de protección social de estos trabajadores, como se ha visto, los cambios legislativos que se han ido introduciendo evitan la inconstitucionalidad de la norma. Sin embargo, el principal debate en esta materia es el de la suficiencia de las prestaciones y el mantenimiento del poder adquisitivo de sus beneficiarios. La aplicación de fórmulas de actualización, como el factor de sostenibilidad o el índice de revalorización genera cierta inseguridad jurídica en esta materia. Por ello sería necesario buscar alternativas o

\footnotetext{
${ }^{119}$ RUANO ALBERTOS, S. (2017), ob. cit., p. 37

${ }^{120}$ Redactado conforme al art. 10 Real Decreto-ley 8/2019, de 8 de marzo, de medidas urgentes de protección social y de lucha contra la precariedad laboral en la jornada de trabajo

${ }^{121}$ CABEZA PEREIRO, J.; LOUSADA AROCHENA, F. (2018), ob. cit., p. 425. 
medios complementarios de subsistencia que permitan eludir el riesgo de sostenibilidad del sistema y la suficiencia de las prestaciones $^{122}$.

Por último, dada la conexión del contrato a tiempo parcial con la conciliación familiar y laboral, el establecimiento de los contrapesos requiere para su correcto funcionamiento, instaurar un modelo de cuidado y atención a la familia corresponsable, superando el modelo de conciliación imperante en España desde hace décadas que pese a los parches introducidos no han solucionado el problema de fondo: la atención al cuidado de familiares sigue siendo un rol atribuido principalmente a las mujeres. En este sentido ya he abogado en alguna ocasión por una necesaria actuación legislativa en dos frentes. En primer lugar, se requiere una intervención en la gestión del tiempo de trabajo, mediante la racionalización de los tiempos de prestación de servicios, posibilitando reducir los tiempos de presencia y permanencia en la empresa a través de la eliminación de la cultura del presentismo y la plena dedicación, introduciendo una mayor flexibilidad horaria, facilitando el teletrabajo.... La segunda actuación debe incidir en un sistema de derechos de conciliación más igualitario, con el objetivo de conseguir un reparto de los tiempos familiares y laborales ejercidos indistintamente y en las mismas condiciones por trabajadores y trabajadoras ${ }^{123}$. Pues bien, el anteriormente citado Real Decreto-ley $6 / 2019$, que ha entrado en vigor mientras se escriben estas líneas, ha dado algún paso en esta dirección. Especialmente se avanza en materia de corresponsabilidad, estableciendo un nuevo régimen de permisos por nacimiento y cuidado de menores de 12 meses, de 16 semanas de duración, iguales e intransferibles para ambos progenitores, que se irá estableciendo de forma gradual, partiendo de las 8 semanas para el otro progenitor en el momento de la entrada en vigor hasta las 16 semanas en el año 2021; y mejorando el régimen jurídico relativo al permiso de lactancia (37.4 ET) y la excedencia por cuidado de hijos y familiares (46.3 ET). Por el contrario, pese a que se modifica el art. 34.8 ET para favorecer la adaptación de jornada por conciliación, sigue pendiente una intervención legislativa decidida en materia de gestión del tiempo de trabajo en los términos expresados anteriormente.

\section{Bibliografía}

ALBIOL MONTESINOS, I.; CAMPS RUIZ, L. M.; GOERLICH PESET, J. M. (2001), La reforma laboral en el Real Decreto Ley 5/2001, Valencia: Tirant lo Blanch.

ALFONSO MELLADO, C. L. (2010), Las actuaciones para incrementar la flexibilidad interna, en ALFONSO MELLADO, C. L.; BLASCO PELLICER, A.; CAMPS RUIZ, L. M.; GOERLICH PESET, J. M., La reforma laboral en la Ley 35/2010, Valencia: Tirant lo Blanch.

${ }^{122}$ ESPÍN SÁEZ, M. (2016), ob. cit., p. $18 / 18$

${ }^{123}$ GARCÍA TESTAL, E.; ALTÉS TÁRREGA, J. A (2018), La discriminación por razón de género en relación con los permisos de maternidad y paternidad: La STC 111/2018, de 17 de octubre, Diario La Ley, (9312). 
ALONSO FERNÁNDEZ, J. J; DEVESA CARPIO, J. E.; DEVESA CARPIO, M.; DOMÍNGUEZ FABIÁN, I.; ENCINAS GOENECHEA, B.; MENEU GAYA, R. (2015), El Tribunal de Justicia de la Unión Europea no aprecia discriminación en la fórmula de integración de lagunas para los contratos a tiempo parcial [en línea], Revista Aranzadi Unión Europea, (5).

ÁLVAREZ CUESTA, H. (2018), Discriminación indirecta en el desempleo en el contrato a tiempo parcial "vertical" en España. Asunto "Espadas Recio" [en línea], Revista Aranzadi Unión Europea, (2).

ARUFE VARELA, A. (2012), Los minijobs alemanes. Un estudio de su régimen jurídico, laboral y de Seguridad Social, comparado con el trabajo marginal español, Revista Española de Derecho del Trabajo, (155), pp. 17 y ss.

BELTRÁN DE HEREDIA RUIZ, I. (2013), «Principio de voluntariedad» ex art. 12.4.e) ET: Un obstáculo (infranqueable) para la reducción de jornada ex arts. 41 y 47 ET, Actualidad Laboral, (6). Recuperado de BD La Ley Digital, Ref. LA LEY 2899/2013.

BELTRÁN DE HEREDIA RUIZ, I. (2015), Directiva 97/81 sobre trabajo a tiempo parcial: conversión de tiempo parcial a tiempo completo, síi; conversión de tiempo completo a parcial, no (comentario a la SSTJUE 15.10.2014, C221/2013, Revista de Información Laboral, (2), pp.

BELTRÁN DE HEREDIA RUIZ, I. (2015, 5 de marzo), Reducción de jornada, voluntariedad y artículo 41 ET: ¿un nuevo ejemplo para la discusión [entrada de blog], Una mirada crítica a las relaciones laborales? Blog de Derecho del Trabajo y de la Seguridad Social. Recuperado de https://ignasibeltran.com/2015/03/05/reduccion-dejornada-voluntariedad-y-articulo-41-et-un-nuevo-ejemplo-para-la-discusion/

BELTRÁN DE HEREDIA RUIZ, I. (2015, 7 de septiembre), ¿La reducción de jornada unilateral no es una novación del contrato de trabajo en otro a tiempo parcial [entrada de blog], Una mirada crítica a las relaciones laborales? Blog de Derecho del Trabajo y de la Seguridad Social. Recuperado de https://ignasibeltran.com/2015/09/07/la-reduccionde-jornada-unilateral-no-es-una-novacion-del-contrato-en-otro-a-tiempo-parcial/

BLASCO PELLICER A.; ALEGRE NUENO, M. (2010) La reforma de 2010, Revista jurídica de la Comunidad Valenciana (36), pp. 11-46.

BLASCO PELLICER, A. (2007), Los procedimientos de regulación de empleo, Valencia: Tirant lo Blanch.

BOTE ÁlVAREZ-CARRASCO, V.; CABEZAS ARES, A. (2012), Conciliación y contrato a tiempo parcial en España: Efectos de la Crisis, Pecvnia, (14), pp. 207-218.

CABEZA PEREIRO, J. (2013), El trabajo a tiempo parcial y las debilidades del modelo español, Albacete: Bomarzo

CABEZA PEREIRO, J.; LOUSADA AROCHENA, F. (2018), El trabajo a tiempo parcial: algunos comentarios valorativos, Derecho de las Relaciones Laborales, (4), pp. 423-435. 
CALlAU DALMAU, P. (2018), Alcance del principio de proporcionalidad en el marco de las relaciones laborales y su incidencia en el trabajo a tiempo parcial, IUSlabor, (1), pp. 253-280.

CALLADU DALMAU, P. (2018), El principio de voluntariedad como presupuesto sustantivo del trabajo a tiempo parcial, Lan Harremanak, (39), pp. 188-212.

CALVO GALLEGO, F. J.; VALVERDE ASENCIO, A. (2001), La nueva regulación del contrato a tiempo parcial y del contrato de relevo, en Temas Laborales (61), pp. 149200.

CASAS BAAMONDE, M. E. (2017), Distribución irregular de la jornada, flexibilidad del tiempo de trabajo y tiempo de vida personal y familiar, Revista Jurídica de la Universidad de León, (4), pp. 3-24.

CAVAS MARTÍNEZ, F.; FERNÁNDEZ ORRICO, F. J. (2009), Medidas urgentes para el fomento y el mantenimiento del empleo y para la protección de las personas desempleadas, Aranzadi Social (2). Recuperado de BD Aranzadi Instituciones, Ref. BIB 2009/421.

CES (2017), Economía, Trabajo y Sociedad. Memoria sobre la situación socioeconómica y laboral. España 2016 [CD-ROM], Madrid: CES

CES (2018), Economía, Trabajo y Sociedad. Memoria sobre la situación socioeconómica y laboral. España 2017 [CD-ROM], Madrid: CES.

COMISIÓN EUROPEA (2017), Informe sobre España 2017, con un examen exhaustivo relativo a la prevención y la corrección de los desequilibrios macroeconómicos. SWD(2017) 74 final [en línea]. Recuperado de https://ec.europa.eu/info/sites/info/files/2017-european-semester-country-report-spaines.pdf

CRUZ VILLALÓN, J. (2007), Modificación del tiempo de trabajo, Revista de Derecho Social (38), pp. 29-48.

CRUZ VILLALÓN, J. (2010) La flexibilidad interna en la reforma laboral de 2010, Relaciones Laborales (21), pp. 125-166.

CRUZ VILLALÓN, J. (2008), Modificación del tiempo de trabajo s en APARICIO TOVAR, J.; LÓPEZ GANDÍA, J. (Coords.), Tiempo de trabajo, Albacete: Bomarzo.

ESPÍN SÁEZ, M. (2015), El contrato a tiempo parcial: de la oportunidad de generar empleo a la precariedad en el empleo, Revista Jurídica de la Universidad Autónoma de Madrid, 1(31), pp. 137-162.

ESPÍN SÁEZ, M. (2016), El contrato a tiempo parcial ¿la conciliación en los tiempos de precariedad? [en línea], Revista de Información Laboral, (12). Recuperado de BD Aranzadi Instituciones, Ref. BIB 2017\10563.

FERNÁNDEZ POL, F. (2014), Trabajo a tiempo parcial y desempleo: problemáticas actuales y perspectivas de futuro [en línea], Actualidad Laboral (11).

FERRADANS CARAMES, C. (2006), El contrato de trabajo a tiempo parcial. Difícil equilibrio entre flexibilidad y seguridad, Cizur Menor (Navarra): Thomson ReutersAranzadi. 
GARCÍA TESTAL, E.; ALTÉS TÁRREGA, J. A. (2010). Contrato a tiempo parcial, reducción de jornada y crisis económica, en CAMPS RUIZ, L. M.; RAMÍREZ MARTÍNEZ, J. M.; SALA FRANCO, T. (Coords.), Crisis, Reforma y Futuro del Derecho del Trabajo (pp. 133-148), Valencia: Tirant lo Blanch.

GARCÍA TESTAL, E.; ALTÉS TÁRREGA, J. A. (2015), El uso de las modalidades contractuales como medida de fomento del empleo juvenil y prolongación de la vida laboral [en línea], Revista de Información Laboral, (2).

GOERLICH PESET, J. M. (2007), El concepto de modificación sustancial de las condiciones de trabajo en la jurisprudencia del Tribunal Supremo, Aranzadi Social (5). Recuperado de BD Aranzadi Instituciones, Ref. BIB 2007/1694.

GONZÁLEZ DEL REY RODRÍGUEZ, I. (2015), Ley General de Seguridad Social y trabajo a tiempo parcial: Sentencia TC 253/2004, de 22 de diciembre, en GARCÍA MURCIA, J. (Dir.), El control de constitucionalidad de las normas laborales y de Seguridad Social, Cizur Menor (Navarra): Thomson Reuters Aranzadi. S i349.2 CON

GONZÁLEZ DEL REY RODRÍGUEZ, I. (2017), Los principios de voluntariedad e igualdad en el trabajo a tiempo parcial, Documentación Laboral, (110), pp. 77-92

LOUSADA AROCHENA, J. F. (2001), El principio de voluntariedad en el nuevo régimen legal del trabajo a tiempo parcial, Aranzadi Social (6). Recuperado de BD Aranzadi Instituciones, Ref. BIB 2001\865.

LOUSADA AROCHENA, J. F. (2014), El trabajo a tiempo parcial en el Real Decreto Ley 16/2013, de 20 de diciembre, Nueva Revista Española de Derecho del Trabajo (162), pp.

MARTÍNEZ YAÑEZ, N. M. (2014), Las horas complementarias como instrumento de gestión flexible del contrato de trabajo a tiempo parcial, Temas Laborales, (126), pp. 91-129.

MERINO SENOVILLA, H. (1999), El trabajo a tiempo parcial: La nueva delimitación y las líneas fundamentales de su contenido, en Revista de Derecho Social (5), pp. 221230.

MIÑARO YANINI, M. (2014), El contrato a tiempo parcial tras sus últimas reformas: flexibilidad rayana en la distorsión de su esencia, Relaciones Laborales (3). Recuperado de BD La Ley Digital, Ref. LA LEY 936/2014

MIRANZO DÍEZ, J. J. (2009), Reducción de jornada en el contrato a tiempo parcial, modificación sustancial de las condiciones de trabajo, y vías procesales para recurrir, Aranzadi Social (10), recuperado de BD Aranzadi Instituciones, Ref. BIB 2009/866.

MOLINA NAVARRETE, C. (2014), Flexibilidad en la gestión del tiempo de trabajo y conciliación de la vida laboral y familiar: a propósito de la nueva regulación del empleo parcial", Documentación Laboral, (100), pp. 13-36.

MONEREO PÉREZ, J. L. (2009), Estrategias de «ajuste», «reestructuración»y «flexibilidad laboral». Modelos normativos, Tribuna Social (227), pp. 9-26. 
MURCIA CLAVERÍA, A. (2017), La reducción de jornada como modificación sustancial de condición de trabajo, el principio de voluntariedad y la garantía de indemnidad, Nueva Revista Española de Derecho del Trabajo, (203), pp. 271-278.

NORES TORRES, L. E. (2000), El período de consultas en la reorganización productiva empresarial, Madrid: CES.

NUÑEZ-CORTÉS CONTRERAS, P. (2016), Puntos críticos en relación al principio de voluntariedad en el contrato a tiempo parcial, Revista General de Derecho del Trabajo y de la Seguridad Social, (42).

NUÑEZ-CORTÉS CONTRERAS, P. (2016), Puntos críticos en relación al principio de voluntariedad en el contrato a tiempo parcial, Revista General de Derecho del Trabajo y de la Seguridad Social, (42), pp. 233-255, pp. 234 y ss.

ODRIOZOLA LANDERAS, M. A. (1998), Situación legal de desempleo parcial como consecuencia de la reducción de la jornada de trabajo, Estudios Financieros. Revista de Trabajo y Seguridad Social (181).

PALOMINO SAURINA, P. (2016), Aspectos relevantes de las horas complementarias en el trabajo a tiempo parcial, Nueva Revista Española de Derecho del Trabajo (191), pp. 129-144.

PANIZO ROBLES, J. A. (2009), Medidas laborales contenidas en el Real DecretoLey $2 / 2009$, de 6 de marzo, de medidas urgentes para el mantenimiento y el fomento del empleo y la protección de las personas desempleadas, en Tribuna Social (220), pp. 1022.

PÉREZ DE LOS COBOS ORIHUEL. F.; AGUILERA IZQUIERDO, R..; GARCÍA PIÑEIRO, N.; THIBAULT ARANDA, J. (2009), El Real Decreto-Ley 2/2009 de medidas urgentes en materia de empleo: un análisis de urgencia [en línea], Diario La Ley (7144). Recuperado de http://diariolaley.laley.es.

PÉREZ DEL PRADO, D. (2014), El trabajo a tiempo parcial: ¿una solución al problema del desempleo? [en línea], Revista de Información Laboral, (5).

RODRÍGUEZ CARDO, I. A. (2018), Igualdad y no discriminación en el trabajo a tiempo parcial: la pertinencia de la perspectiva de género y de la prueba estadística, Derecho de las Relaciones Laborales, (2), pp. 153-172.

ROQUETA BUJ, R. (2002), La protección social de los trabajadores a tiempo parcial, Madrid: CES.

ROQUETA BUJ, R. (2012), La flexibilidad interna en AA. VV. La reforma laboral en el Real Decreto-Ley 3/2012, Valencia: Tirant lo Blanch.

RUANO ALBERTOS, S. (2017), El contrato a tiempo parcial: las posibles perversiones en su utilización. Revista General de Derecho Del Trabajo y de La Seguridad Social, (46), pp. 1-47.

SALA FRANCO, T.; ROQUETA BUJ, R. (2018), Propuestas para un debate sobre la reforma del contrato a tiempo parcial, Derecho de las Relaciones Laborales, (4), pp. 410422. 
SALA FRANCO, T. (2000), Los principios de ordenación del contrato de trabajo a tiempo parcial, en CASAS BAAMONDE, M. E.; VALDÉS DAL-RÉ, F. (Coords.) Los contratos de trabajo a tiempo parcial, Valladolid.

SALA FRANCO, T.; ALTÉS TÁRREGA, J. A.; LÓPEZ BALAGUER, M. (2018), El tiempo de trabajo y la conciliación laboral, personal y familiar, en SALA FRANCO, T. (Coord.) Propuestas para un debate sobre la reforma laboral, Madrid: Francis Lefebvre.

SALLADARRÉ, F.; HLAIMI, S. B. (2014), Las mujeres y el trabajo a tiempo parcial en los países europeos, Revista Internacional del Trabajo, 133(2), pp. 325-343.

SANCHEZ TORRES, E. (2011), La incidencia de la prueba estadística y del "principio de transversalidad" en la adjetivación de la responsabilidad empresarial en materia de igualdad y no discriminación [en línea], Diario La Ley, (7667).

SANTIAGO REDONDO, K. (2011), Reducción de jornada y suspensión del contrato en AV La reforma del mercado de trabajo de 2010, Madrid: Editorial Reus.

SCHULZ JIMENO (2009), La Kurzarbeit — Reducción del tiempo de trabajo (RTT) como medida anticrisis en Alemania. Recuperado de http://www.madridsindical.org/comunes/recursos/99922/doc16774_La_Kurzarbeit,_red uccion_del_tiempo_de_trabajo,_como_medida_anticrisis_en_Alemania.pdf

SIERRA HERNAIZ, E.; GOÑI SEIN, J. L. (2014), El empleo a tiempo parcial desde la perspectiva de género [en línea], Revista de Derecho Social, (28). Recuperado de BD Tirant on Line, Ref. TOL599.845

SIRVENT HERNÁNDEZ, N. (2016), El régimen jurídico de la jornada complementaria en el contrato de trabajo a tiempo parcial tras las modificaciones introducidas por el Real Decreto-Ley 16/2013, de 20 de diciembre”. Trabajo y Derecho (5).

TAPIA HERMIDA, A., (2014) ¿Es posible proceder a la transformación de una relación laboral a tiempo parcial en una relación laboral a tiempo completo aun contra la voluntad del trabajador?, Revista de Trabajo y Seguridad Social. CEF, (381), pp. 177181.

TASCÓN LÓPEZ, R. (2017), El contrato a tiempo parcial como instrumento de flexibilidad interna quasi absoluta, Documentación Laboral, (111), pp. 131-155.

TATAY PUCHADES, C. (2002), Seguridad Social y empleo atípico, en OISS, Empleo y Seguridad Social. La incidencia del desempleo, el empleo informal y las nuevas formas de empleo en la cobertura y la financiación de los Sistemas de Protección Social (pp. 83248), Madrid: OISS.

VICEDO CAÑADA, L. (2009), De contrato a tiempo completo a contrato a tiempo parcial. Una solución para las PYMES en tiempos de crisis, Madrid: La Ley. 